\title{
Design Optimization of a Transonic-Fan Rotor Using Numerical Computations of the Full Compressible Navier-Stokes Equations and Simplex Algorithm
}

\author{
M. A. Aziz, ${ }^{1}$ Farouk M. Owis, ${ }^{2}$ and M. M. Abdelrahman ${ }^{2}$ \\ ${ }^{1}$ Aircraft Engineering Department, Institute of Aviation Engineering and Technology, Giza, Egypt \\ ${ }^{2}$ Department of Aerospace Engineering, Faculty of Engineering, Cairo University, P.O. Box 12613, Giza, Egypt \\ Correspondence should be addressed to Farouk M. Owis; fowis@eng.cu.edu.eg
}

Received 30 June 2013; Revised 8 January 2014; Accepted 20 January 2014; Published 24 March 2014

Academic Editor: S. Acharya

Copyright (c) 2014 M. A. Aziz et al. This is an open access article distributed under the Creative Commons Attribution License, which permits unrestricted use, distribution, and reproduction in any medium, provided the original work is properly cited.

\begin{abstract}
The design of a transonic-fan rotor is optimized using numerical computations of the full three-dimensional Navier-Stokes equations. The CFDRC-ACE multiphysics module, which is a pressure-based solver, is used for the numerical simulation. The code is coupled with simplex optimization algorithm. The optimization process is started from a suitable design point obtained using low fidelity analytical methods that is based on experimental correlations for the pressure losses and blade deviation angle. The fan blade shape is defined by its stacking line and airfoil shape which are considered the optimization parameters. The stacking line is defined by lean, sweep, and skews, while blade airfoil shape is modified considering the thickness and camber distributions. The optimization has been performed to maximize the rotor total pressure ratio while keeping the rotor efficiency and surge margin above certain required values. The results obtained are verified with the experimental data of Rotor 67. In addition, the results of the optimized fan indicate that the optimum design is found to be leaned in the direction of rotation and has a forward sweep from the hub to mean section and backward sweep to the tip. The pressure ratio increases from 1.427 to 1.627 at the design speed and mass flow rate.
\end{abstract}

\section{Introduction}

Transonic fans are widely used in recent aircraft engines to obtain maximum pressure ratios per stage. High stage pressure ratios are important to reduce the engine weight, size, and operational costs. Performance of transonic fan has reached a high level but further improvements are required by engine manufacturers.

Recently, axial flow fans have been developed to a point, where stage efficiency has exceeded $90 \%$. The goal of the current study is to maximize the total pressure ratio and to satisfy the required efficiency and mass flow rate. High fidelity methods are used for the design optimization of transonic fans of high pressure ratios. Numerical methods offer a feasible approach to solve complex nonlinear optimization problems involving a multitude of design variables and constraints in a systematic and efficient manner. Application of these computational design optimization approaches for fan blade designs can reduce design cost and design cycle and increase efficiency of jet engines [1].

The problem of the design validation and optimization of transonic compressors using numerical solution of the turbulent flow equations has been under investigation by several researchers [2-4]. Hah and Reid [5] conducted a numerical study based on the three-dimensional Reynoldsaveraged Navier-Stokes equation to investigate the detailed flow physics inside a transonic compressor. Ning and $\mathrm{Xu}$ [6] performed a numerical investigation for the flow over a transonic compressor rotor using an implicit 3D flow solver with one-equation Spalart-Allmaras turbulence model.

The objective of the current study is the optimization of the rotor blade shape for a transonic fan to maximize the rotor pressure ratio while satisfying certain geometrical and performance constraints. A parametric study for the fan blade geometry is performed using a preliminary design method for transonic fans to find a suitable starting point for the high fidelity design method [7]. Experimental correlations are 
used to predict the shock losses, profile losses, and deviation angle during the preliminary design and off-design steps. The multiple circular arc (MCA) airfoil shape is found to be a good choice to design compressor blades during the preliminarily steps.

The numerical simulations are done using the CFDRCACE multiphysics module, which is a pressure-based solver. The code solves the time-dependent, Reynolds-averaged Navier-Stokes equations for turbulent, compressible flows using a finite volume, time-marching approach on multizone, structured grids. Spatial accuracy is nominally second-order upwind formulation. Steady flows are simulated through an iterative process using local time stepping. Turbulence is computed using the Standard $k-\varepsilon$ model.

For relative inlet Mach numbers in the order of 1.3 and higher, the most important design intent is to reduce the Mach number in front of the passage shock. This is of primary importance due to the strongly rising pressure losses with increasing preshock Mach number and because of the increasing pressure losses due to the shock/boundary layer interaction or shock-induced separation. The reduction of the preshock Mach number can be achieved by zero or even negative curvature in the front part of the blade suction side and by a resulting precompression shock system reducing the Mach number upstream of the final strong passage shock. The thickness is also kept very low, about $2 \%$ of chord for the tip section of a transonic fan. Besides inducing energy losses, the presence of shock waves makes transonic compressors particularly sensitive to variations in blade section design. An investigation of cascade throat area, internal contraction, and trailing edge effective camber on compressor performance shows that small changes in mean line angles, and consequently in the airfoil shape and passage area ratios, significantly affect the performance of transonic blade rows [8].

One of the most important airfoil design parameters affecting the aerodynamics of transonic blading is the chordwise location of maximum thickness. Good performance is obtained for the lower shock front losses with the finer section which results when the location of the maximum thickness is moved aft. An optimum maximum thickness location is assumed to exist in the range of $55 \%$ to $60 \%$ of the chord length for transonic fan rotors [9]. Not only the position of maximum thickness but also the airfoil thickness has a significant impact on the aerodynamic behavior of transonic compressor rotors.

The flow field in a compressor is not influenced by the two-dimensional airfoil geometry. The three-dimensional shape of the blade is also of great importance, especially in transonic compressor rotors where an optimization of shock structure and its interference with secondary flows is required. Many experimental and numerical studies have been done for the design and analysis of three-dimensional shaped transonic blading (e.g., $[10,11])$.

\section{Mathematical Model}

An optimization algorithm is used to maximize the total pressure for the fan rotor blades using the CFD-RC package. The rotor blade geometry is parameterized in order to facilitate its handling through the design process. The level of success in parameterizing the blade is dependent on two factors. The first factor is the flexibility and amount of coverage of all possible solutions. The second factor is the compactness of the parameters. The more accurate the description of the blade, the bigger the number of parameters. The optimization process is used to determine the following dimensions:

(i) thickness distribution of each section at different radii,

(ii) camber distribution of each section at different radii,

(iii) staking line of the different blade sections from hub to tip,

(iv) blade twist distribution over the staking line.

2.1. Classification of Design Optimization Parameters. The prementioned design parameters are the factors affecting blade shape optimization process. They can be classified into two main groups. The first group is the hub-to-shroud $(z-r$ or meridional) plane group. The second group is the bladeto-blade $(r-\theta)$ plane group and the mixing between bladeto-blade and hub-to-shroud planes group. In the following sections, the details of each group are described and their effects on the rotor blade performance are investigated.

2.2. Hub-to-Shroud Plane Group. The hub-to-shroud (meridional) plane group geometry is parameterized as follows:

(1) blade inlet and exit hub radius,

(2) blade inlet and exit tip radius,

(3) equation describing the hub curve in the meridional plane,

(4) equation describing the tip curve in the meridional plane.

This classification is based on the direct physical dimensions and their effect on the fan performance. Inlet hub and tip radii together are affecting the inlet area and so the average inlet Mach number. The inlet tip radius affects the peripheral speed and, consequently, the value of relative Mach number at the tip, which should be kept as low as possible to minimize losses in this part. The equations describing the hub and tip curves in the meridional plane can affect the pressure gradient on the hub and tip surfaces, boundary layer growth, and the associated velocity profile. It is difficult to manipulate these parameters efficiently using simple $1 \mathrm{D}$ or even $2 \mathrm{D}$ models. It should be manipulated using 3D CFD solvers to account for its different impacts on the flow. The meridional plane group is shown in Figure 1.

2.3. Blade-to-Blade Plane Group. The blade-to-blade plane geometry is parameterized as follows:

(1) blades spacing,

(2) equation describing the mean blade camber line, 


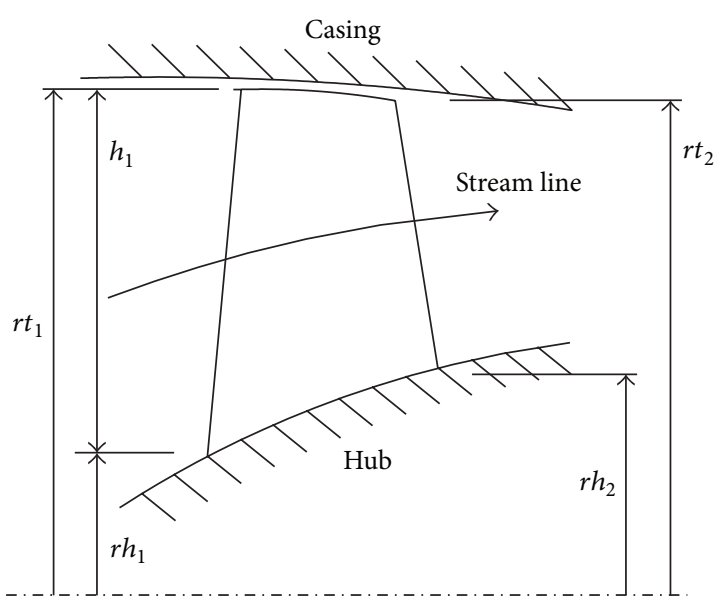

Figure 1: Hub-to-shroud (meridionalplane) group.

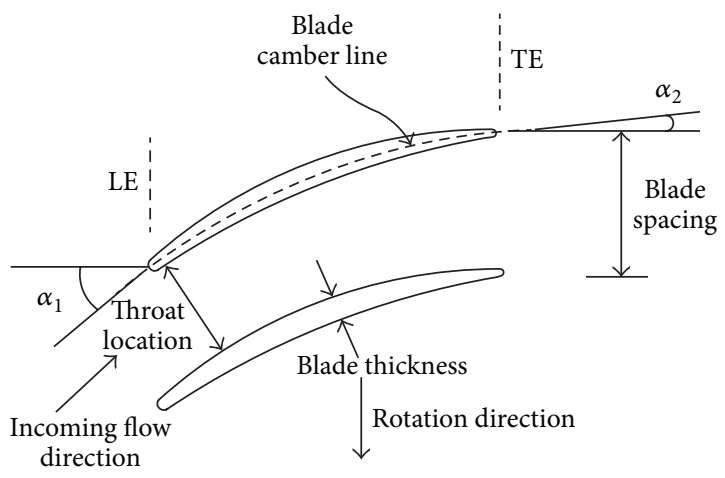

Figure 2: Blade-to-blade plane group.

(3) equation describing the blade thickness distribution along meridional coordinates,

(4) blade chord distribution,

(5) stagger angle.

The first parameter (blades spacing) depends on the number of blades and the radius at this location. Its combined effect with the second and third parameters and blade height determines the chocking conditions. The blade camber, thickness distribution, and the stagger angle determine the blade inlet and exit angles. The blade inlet angle affects directly the velocity triangle at the inlet, flow incidence angle, and relative Mach number. The exit blade angle affects the work of the rotor, through affecting the circumferential absolute exit velocity. Figure 2 shows the blade-to-blade plane group.

2.4. Mixing between Blade-to-Blade Plane Group and Hub-toShroud Plane Group. It is a set of geometry parameters that may appear in the two planes described above. It could be parameterized as follows:

(1) equation describing the axial position of the section staking point over the radial direction,

(2) equation describing the circumferential position of the section staking point over the radial direction.
The first parameter is the staking point axial coordinates, which should cause the blade to sweep back or forward. This sweep has its effect on improving the blade adiabatic efficiency as mentioned by [13]. A recent numerical and experimental work shows that the axial blade curvature can help to influence the shock shape in the meridional plane, inducing the shock to assume the meridional curvature of the blade leading edge. In addition, a considerable impact on the radial outward migration of fluid particles which takes place inside the blade suction side boundary layer after the interaction with the shock has been confirmed. Numerical and experimental analyses carried out to evaluate the performance of a forward swept rotor and an aft swept rotor show that the forward swept rotor has higher peak efficiency and a substantially larger stall margin than the baseline unswept rotor. The aft swept rotor has similar peak efficiency with a significantly smaller stall margin [14].

Detailed analyses of the measured and calculated flow fields indicate that two mechanisms are primarily responsible for the differences in aerodynamic performance among these rotors. The first mechanism is the change in the radial shape of the passage shock near the casing by the end wall effect, and the second is the radial migration of low momentum fluid to the blade tip region. Similar results are obtained in a parallel investigation which identified the reduced shock/boundary layer interaction, resulting from reduced axial flow diffusion and less accumulation of centrifuged blade surface boundary layer at the tip, as the prime contributor to the enhanced performance with forward sweep [15].

The second parameter is the staking point circumferential coordinates, which should cause the blade lean. As mentioned in $[16,17]$, it is weakening the passage's shock and it is reducing loss core near the tip of the suction surface. A recent numerical work gave a point of view on the impact of blade curvature in transonic compressor rotors, showing how the movement of blade sections in the tangential direction can influence the internal flow field [18, 19]. Another research group investigated the aerodynamic effects induced by several tangential blade curvatures on the same rotor. It is observed that when the curvature is applied towards the direction of rotor rotation, the blade-to-blade shock tends to move more downstream, becoming more oblique to the incoming flow. This reduces the aerodynamic shock losses and entropy generation, showing in some cases a peak efficiency increment of over $1 \%$ at design speed [20]. Similar results were previously obtained using a numerical optimization algorithm [21].

Higher performance can be achieved using a proper combination of two orthogonal blade curvatures, that is, the use of a blade curved both axially and tangentially and swept and leaned at the same time as applied in the current study. Figure 3 shows the blade-to-blade and hub-to-shroud planes mixing group.

2.5. Blade Thickness Distribution and Camber Line Curve Treatment. The blade camber line curve has a major role in the design problem. It describes the blade angle distribution along the meridional path. The inlet and exit blade angles 


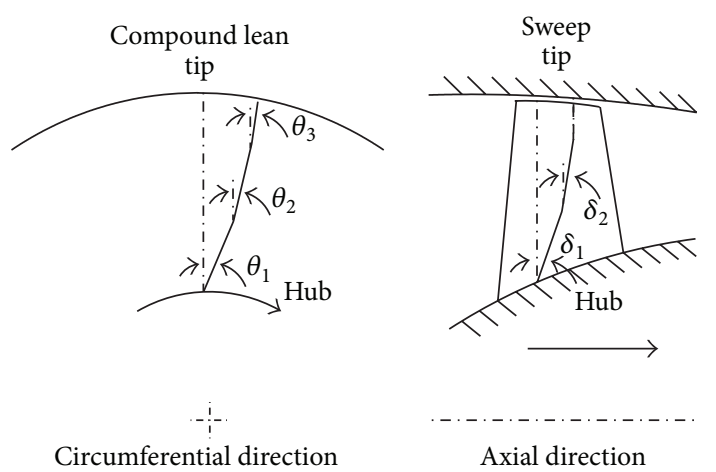

FIgURE 3: Definition of swept and leaned rotor blade geometry.

affect directly the work transferred to the fluid. Describing the camber line could be done using polynomial or Bezier curves. Five- or six-point Bezier curve is sufficient to describe a complex curve, where a polynomial of higher order is needed to do the same job. In the present work, three sections are defined; each section is defined using five-point Bezier curve for description of the camber line curve. That is to say, if every point has two coordinates $(x, y)$, a total number of (30) variables need to be defined. Figure 4 shows the Bezier points used for the description of this curve. In the present work, and for the purpose of simplicity, the number of sections considered is only three sections, where the more sections are recommended. The meridional coordinates are taken as $0 \%$, $25 \%, 50 \%, 75 \%$, and $100 \%$ of the chord length with the first and last points being fixed.

The blade thickness distribution along the meridional coordinates could be described using polynomial or Bezier curve. In the present work, this parameter is investigated using seven-point Bezier curve, where the coordinates of the second and six points in the meridional directions represent the leading and trailing edges radiuses. The remaining points are treated as described above in the camber line treatment. Figure 6 shows a typical blade thickness distribution, using Bezier curve of Figures 4 and 5.

2.6. Section Thickness and Camber Representation. In order to start the optimization for the section thickness and camber distributions, the Bezier control points should be determined. A Bezier curve is defined by a set of control points $P_{n}$, where $n$ is the order. A Bezier curve with 5 control points is a fourthorder curve. The parametric curves may be defined as follow:

$$
y(x)=\sum_{i=0}^{n} b_{i, n}(x) P_{i}, \quad x \in[0,1]
$$

where the control points are $P_{i}, b_{i, n}(x)$ are polynomials defined as

$$
b_{i, n}(x)=\left(\begin{array}{c}
n \\
i
\end{array}\right) x^{i}(1-x)^{n-i},
$$

and the $\left(\begin{array}{c}n \\ i\end{array}\right)$ is the binomial coefficient defined as

$$
\left(\begin{array}{c}
n \\
i
\end{array}\right)=\frac{n !}{i !(n-i) !} \text {. }
$$

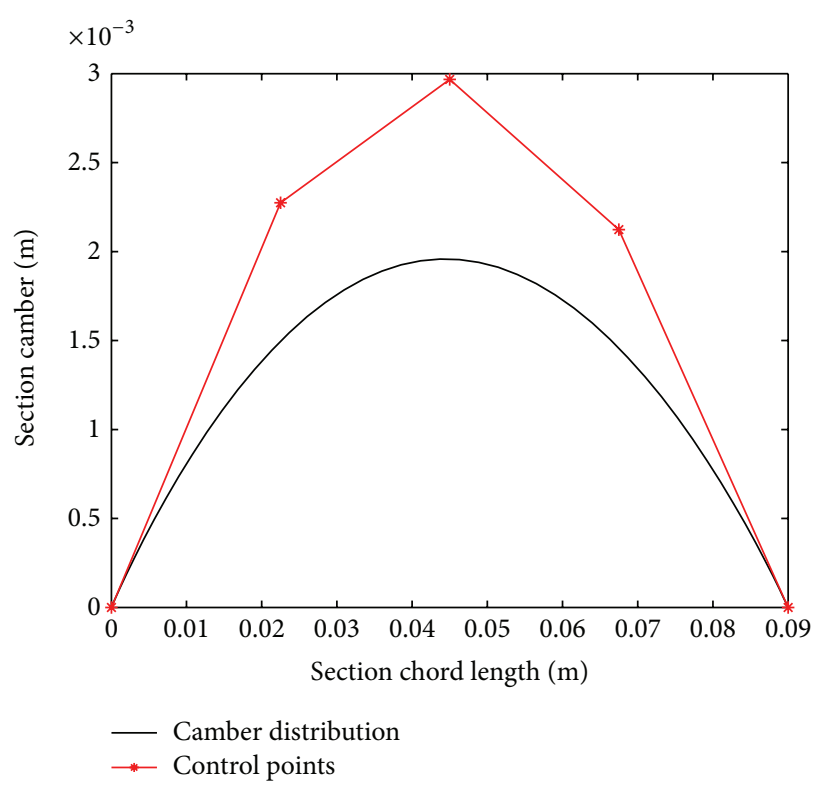

FIGURE 4: Bezier curve describing blade camber line.

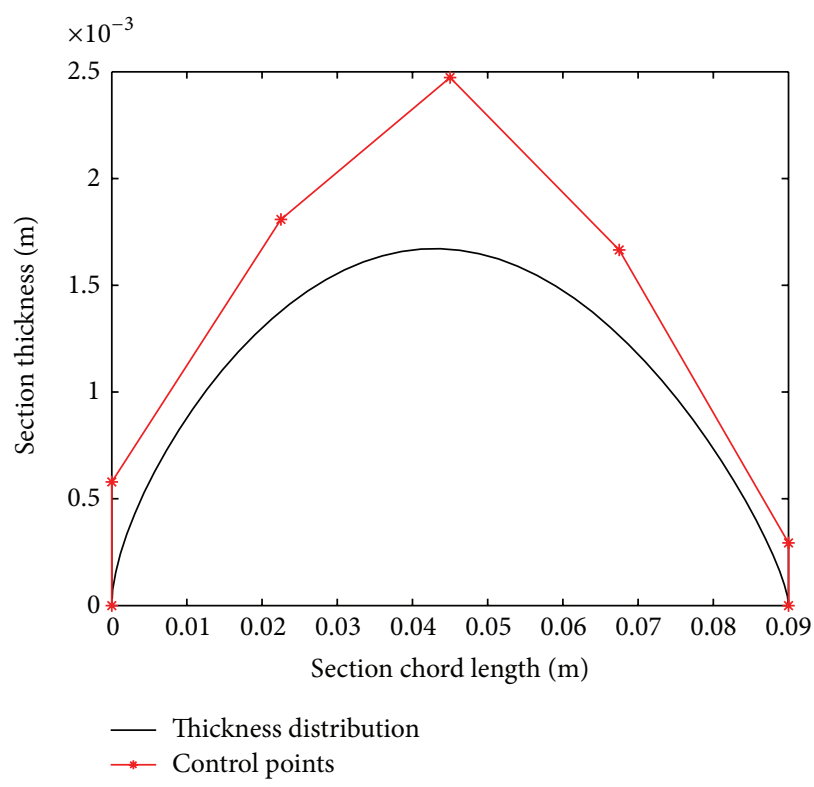

FIgURE 5: Bezier curve describing blade thickness distribution.

There are different methods to find the control points coordinates that accurately represent the section camber and thickness distributions. One method that gives accurate results is that using optimizations algorithm. The algorithms are used to locate the control points with the best fitting to the original curve. Figure 7 is a representation for applying the Particle Swarm Optimization (PSO) [22] on the camber line curve of a famous NASA Rotor 67.

A fixed value for the tip clearance of $1.5 \%$ from blade tip chord is only considered in the current study. The actual behaviour of the rotor blade is affected by the combination of the geometrical parameters together, not by everyone 


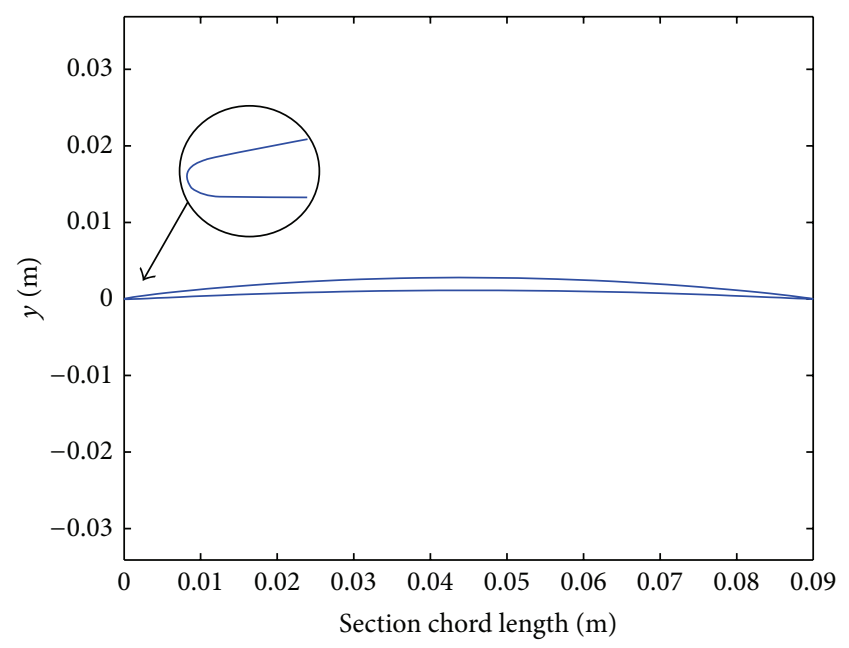

FIgure 6: Typical blade thickness and blade camber line in bladeto-blade plane using Bezier curve.

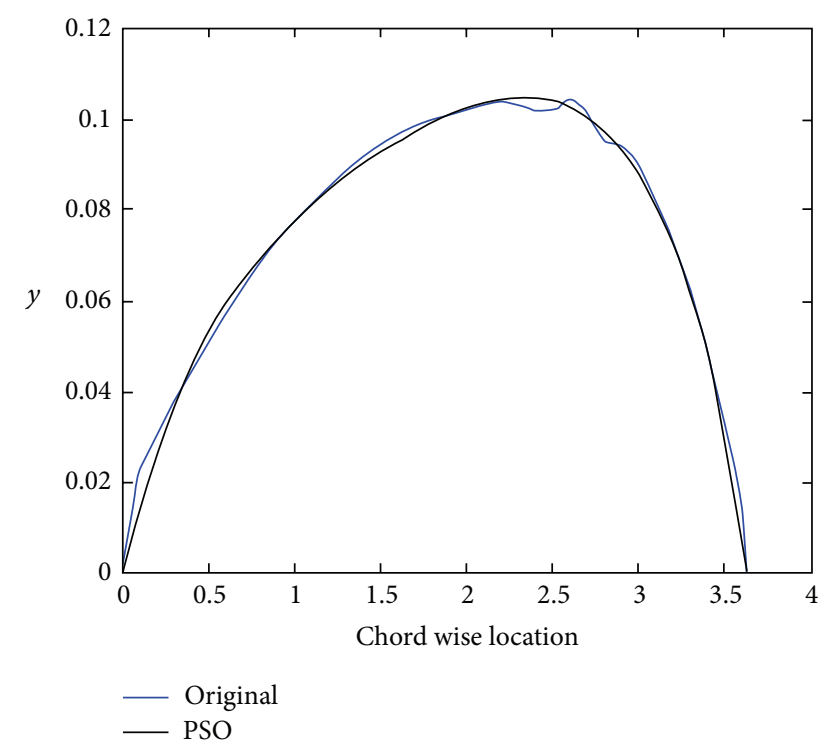

FIGURE 7: Bezier 5 control points representation for the camber line obtained by PSO.

alone. That limits the ability of trusting empirical and simple one-dimensional equations result. This pushes the designer towards the obligatory 3D CFD simulations, which deal with the actual geometry as one unit, combining all the previously mentioned points. The variation of the coordinates of any geometric parameter will lead to a new geometry. Thus, it is easy to manipulate the problem using an optimizer.

\section{The CFD Code}

The CFD analysis or simulation is highly dependent on the boundary conditions because the flow is internal and the boundary conditions are applied in proximity to the complex flow features. The first objective of this section is to describe the subsonic inflow and outflow boundary conditions that

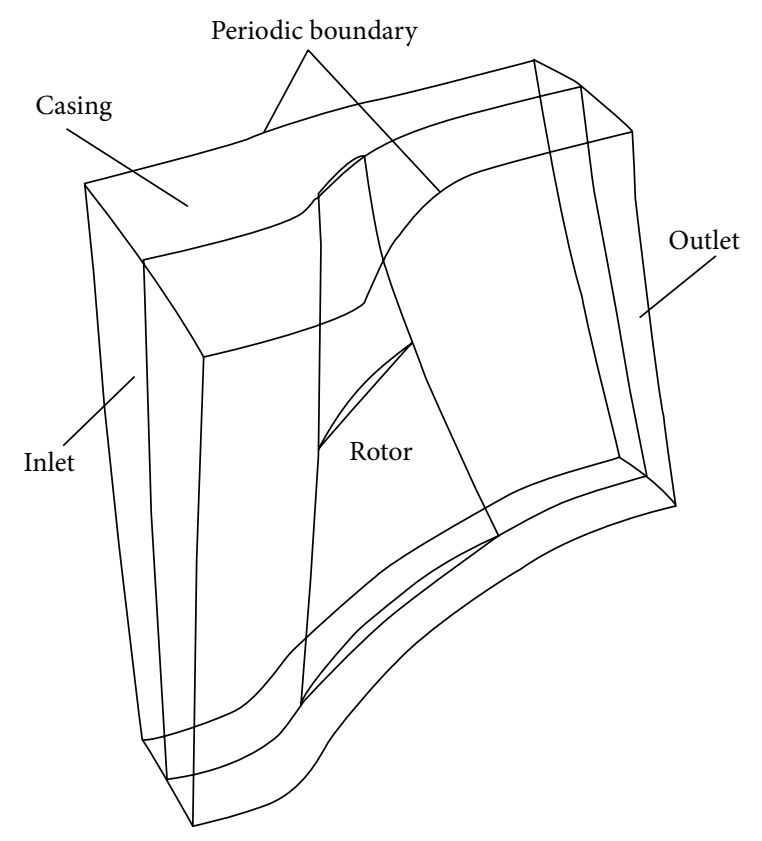

FIGURE 8: The computational domain and boundary conditions.

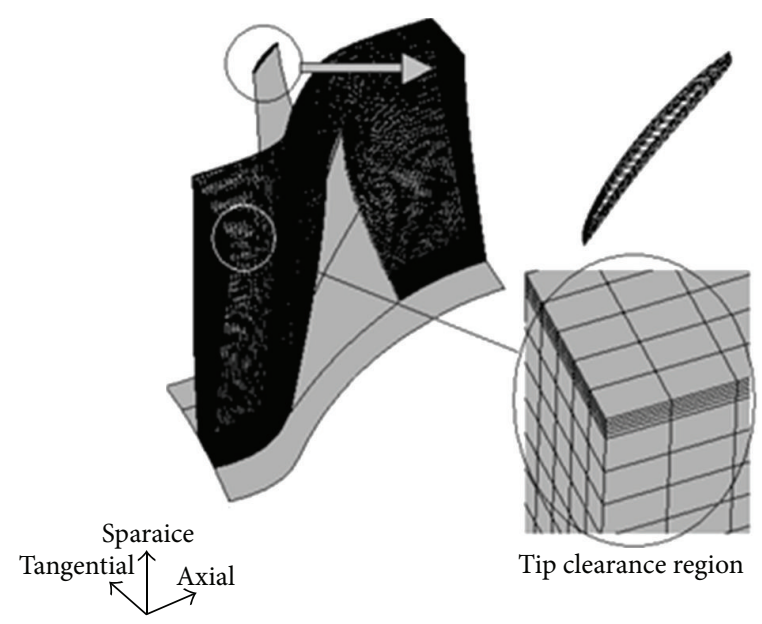

FIGURE 9: Rotor mesh.

have been implemented into the CFD code and applied for the analysis of flows through transonic fans. The second objective is to validate the utilized CFD code CFD-ACE through a comparison of the results with the previous computational and the experimental studies.

The CFDRC-ACE multiphysics module is a pressurebased solver. It solves the time-dependent, Reynoldsaveraged Navier-Stokes equations for turbulent, compressible flows using a finite volume, time-marching approach on multizone, structured grids. Spatial accuracy is nominally second-order upwind formulation. Steady flows are simulated through an iterative process using local time stepping. Turbulence is modeled using the Standard $k-\varepsilon$ model [23]. CFD-ACE is capable of solving flows of speeds ranging from low subsonic flow to relatively high supersonic flow. 


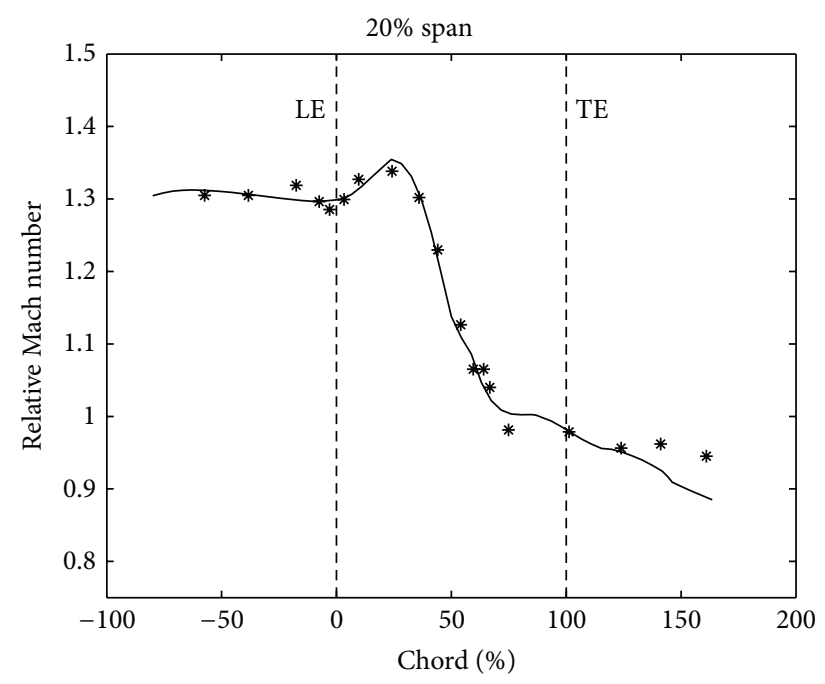

(a)

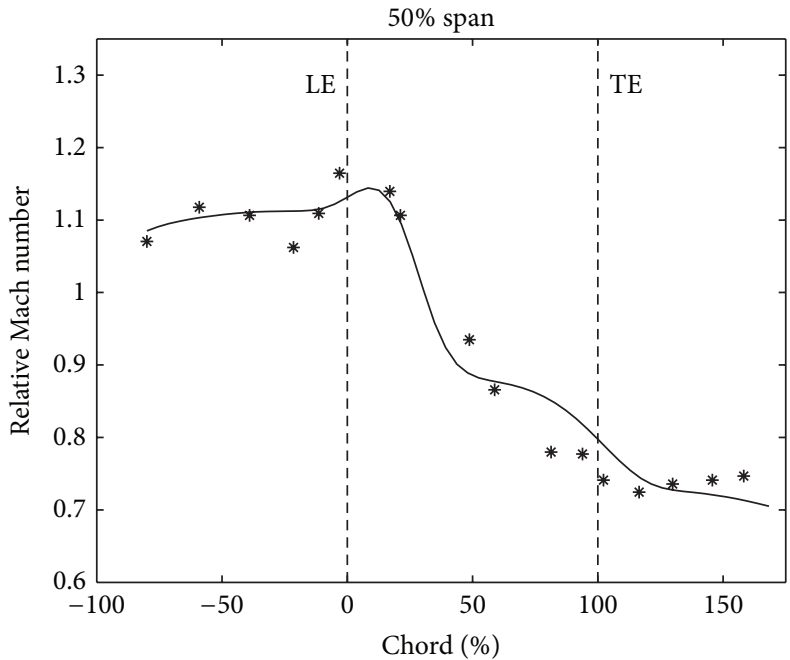

(b)

Figure 10: Comparisons between the experimental data [12] and the present CFD results for the relative Mach number at 20\% and 50\% span measured from the tip section.

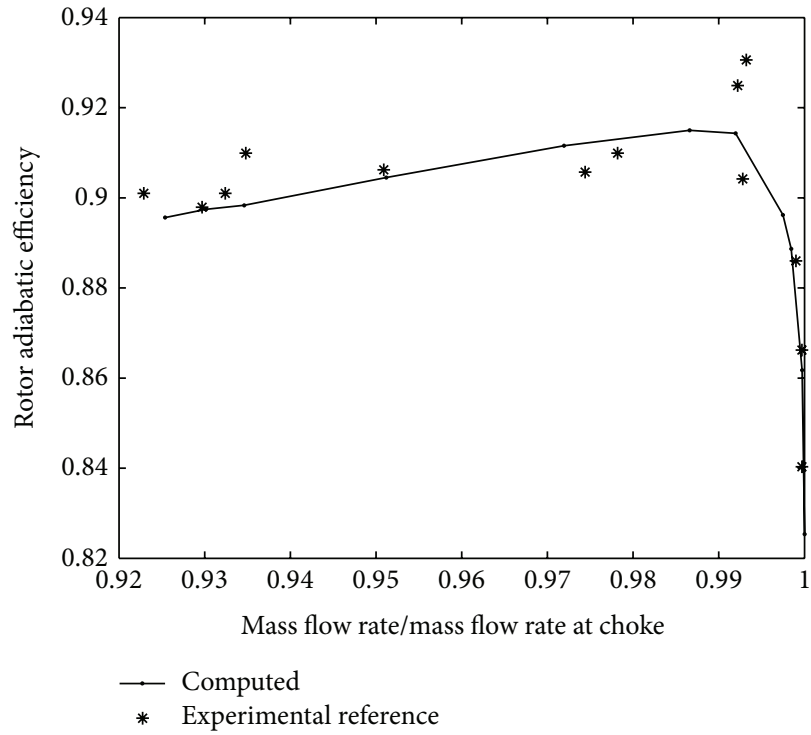

(a)

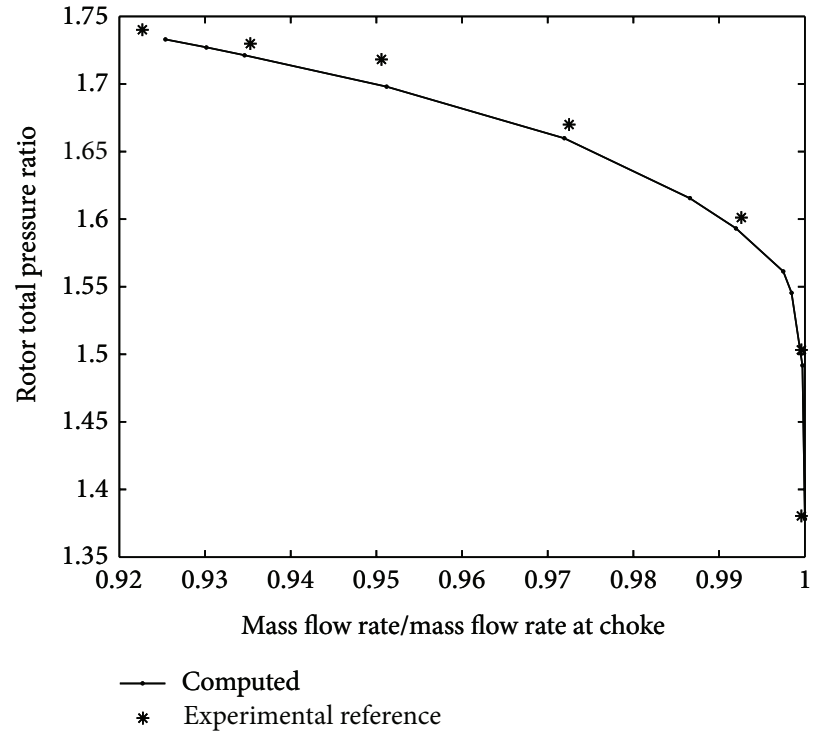

(b)

FIGURE 11: Comparison between the current computations of the rotor pressure ratio and the measured NASA Rotor 67.

The computational domain for the rotor is constructed as a rotating domain. The blade row is represented by a single blade passage considering a $3 \mathrm{D}$ periodic sector along the whole rotor passage as indicated in Figure 8. Standard boundary conditions for subsonic flows are implemented. At the inlet, the flow angles, total pressure, velocity, and total temperature are specified. At the outlet, the average value of the static pressure at the hub is prescribed, whereas circumference pressure gradient is extrapolated to maintain a specified average static pressure. The density and velocity components are extrapolated from interior. On the solid wall, the temperature is set constant as the total temperature at the inlet and the pressure is extrapolated from the interior. The no-slip boundary conditions and the temperature condition are used together to compute the density and total energy. Periodic boundary conditions are applied from blade to blade passage.

Figure 8 is a representation of the boundary conditions specified in the problem. Initially, the flow properties in the computational domain are assumed to be uniform and are set equal to the inlet free stream values. The rotor passage is discretized using three blocks to represent the flow volume 

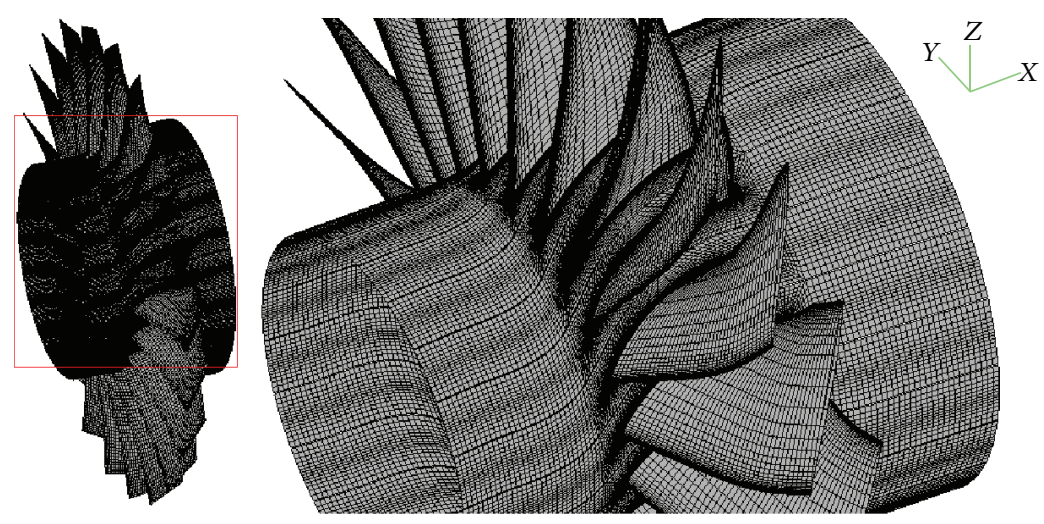

FIGURE 12: Fan rotor structured grid.

around the blade. Two blocks are for the rotor pressure and suction sides and the other block is for the tip region. The first two blocks represent a sector with the blade in the middle.

The geometry and mesh of each block is generated using PYTHON script file in the preprocessor of CFDRC package. The mesh used for the model is mainly structured. Figure 9 shows the rotor and tip clearance region mesh.

3.1. Validation of the CFD Code. The geometry chosen to validate the code is the transonic high-speed axial fan rotor of NASA Rotor 67. This low aspect ratio rotor is the first stage rotor of a two-stage transonic fan designed and tested with laser anemometer measurements at the NASA Glenn Research Center [12]. The geometry and the grid are constructed in the CFDRC geometry module and the boundary conditions are applied in the solver module using PYTHON script file. The simulations are performed for different values of the back pressure to construct the rotor map at the design speed.

At the design mass flow rate, the relative Mach number distribution along the blade-to-blade $50 \%$ passage chord length at $50 \%$ and $20 \%$ span measured from tip section is presented in Figure 10. The figures show good agreement with the experimental data of Rotor 67 . The results indicate that the effect of the shock system inside the rotor passage and at the boundaries is predicted accurately.

Figure 11 compares the computed and the measured rotor maps at the design speed and at different off-design mass flow rates. The numerical simulation reveals that, at design speed, the computed pressure ratio for the rotor agrees very well with the experimental data. However, the maximum efficiency obtained is less about $2 \%$ than that obtained from the experiment. This difference has been observed by other authors. NASA investigations revealed that this is due to the presence of high axial gap in hub annulus line upstream of the blade leading edge, which has detrimental effects on the rotor proprieties [24]. Therefore, we conclude that the numerical simulations performed in the current study predict important flow features and mechanisms.

A grid sensitivity study is performed. The objective is to determine the level at which the solution is invariant with the grid size. The grids used in the simulations are generated using characteristic grid spacing, $h$. The finest grid spacing is denoted as $h_{1}$. For each grid, the simulation results in an observed flow quantity, $f$, such as the total pressure ratio. The change in the quantity $f$ between the grids is expressed in terms of the grid convergence index (GCI). GCI error estimates can be used with minimum of two mesh solutions. It provides less error estimate when used with three mesh solutions [25]. The GCI between a finer grid with spacing $h_{1}$ and coarser grid with spacing $h_{2}$ is defined as

$$
\mathrm{GCI}=\frac{F_{S}\left|\left(f_{2}-f_{1}\right) / f_{1}\right|}{r^{p}-1}
$$

where $r$ is the refinement ratio between the finer grid and coarser grid and $p$ is the order of grid convergence observed in the simulations, and they are given by the following expressions:

$$
\begin{gathered}
r=\frac{h_{2}}{h_{1}}, \\
p=\frac{\ln \left(\left(f_{3}-f_{2}\right) /\left(f_{2}-f_{1}\right)\right)}{\ln (r)} .
\end{gathered}
$$

A factor of safety of $F_{S}=1.25$ is used based on the experience of applying GCI in many situations as indicated by Roache [25]. A second-order solution would have ( $p=$ 2 ). The GCI is a measure of the percentage difference of the computed quantity from the value of the asymptotic numerical value. It approximates an error band and it indicates how much the solution would change with further refinement of the grid. Verification assessment involves performing consistency checks. One such check is that the mass is conserved through the flow domain. For inlets and ducts, mass conservation can be assessed spatially along the streamwise coordinate of the duct. Mass flow bookkeeping tracks the mass flow through the compressor with that of the captured mass flow. The boundary conditions are indirectly verified through comparison of the simulation results to available analytic results for the flow field. The geometry and grid generation for rotor blade are constructed at the geometry module.

A grid sensitivity study is performed to ensure that the baseline grid has adequate sizes to resolve the solid 


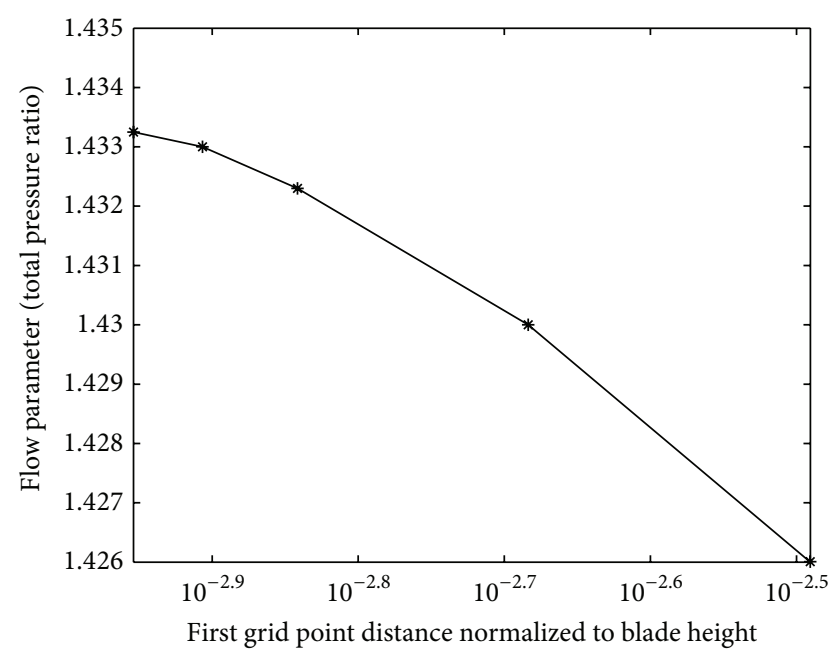

FIGURE 13: Effect of grid spacing on the accuracy of the steady state solution.

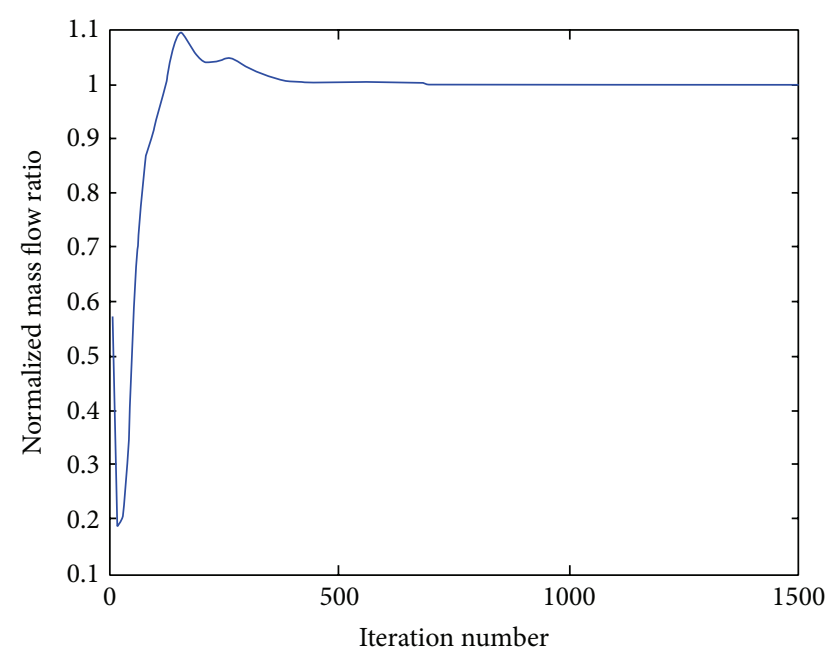

FIGURE 14: Nondimensional mass flow rate convergence history.

wall boundary layers and the shock system [8]. Simulations are conducted on different grids with variable grid points. Table 1 summarizes the sensitivity of the number of cells for structured grids shown in Figure 12. Figure 13 shows the variation of the observed flow quantity (i.e., total pressure ratio) for different grids sizes, while Figure 14 shows the convergence history of the normalized mass flow rate $\left(\dot{m} / \dot{m}_{\text {Design }}\right)$ through the rotor for the grid considered in the design optimization. The computations asymptotically converge after 750 iterations to the same design mass flow rate.

\section{High Fidelity Optimization}

The aim of the present study is to obtain an optimum blade geometry for a given preliminary design of the transonic fan with some geometrical and performance constraints. The final task is to combine all the developed modules in association with the simplex optimization algorithm to complete the optimization cycle. Figure 15 illustrates the sequence of the optimization flowchart with some modifications.

4.1. Optimization Algorithm. The simplex algorithm is used for the optimization process. The algorithm is a direct (nongradient) optimization method and requires only one objective function evaluation per design iteration. The algorithm is robust and is likely to converge. The algorithm is easy to use because it has only three parameters to adjust (initial values of variables, first step size, and minimum and maximum variables values). Some of the algorithm disadvantages are that, as with most algorithms, the algorithm may find a local minimum instead of the global minimum. Different minimum solutions can be found by starting the optimizer at different initial points. Since the simplex algorithm does not use past information to accelerate movement through the design space, convergence can be slow (especially with a large number of design variables).

A simplex is a polygon defined by $(n+1)$ vertices in $n$-dimensional space. For example, in $2 \mathrm{D}$, a simplex is a triangle (Figure 16). The simplex is termed "regular," if its vertices are equidistant. Each vertex of the polygon represents a single design configuration, with design variable values $X(1), X(2), \ldots, X(N)$, each of which corresponds to an objective function value. To progress towards an optimum solution, the simplex algorithm reflects the vertex associated with the worst design through the centroid of the polygon. New design variable values and the associated objective function value define the new point.

As the algorithm progresses through the design space, two setbacks can occur. The first setback occurs, if the current worst design is created in the previous iteration. If this point is again reflected, the algorithm would bounce back and forth between two configurations. The algorithm instead reflects the second worst point. The simplex moves in a different direction, away from the stall point. An objective function that has a steep valley leading to a local minimum will cause the simplex algorithm to cycle infinitely through the same design points at the rim of the valley. The second setback is that when simplex cycles through the same designs over a period of several iterations, the algorithm is stalled. Reducing the physical size of the simplex allows it to fit into the valley and get closer to the minimum solution. The size reduction is done at the first instance of a repeated design.

An initial value for each design variable must be specified. The optimizer uses initial variable values as a starting guess for the optimization studies. These values will be used to create the first design. To start the optimization process, one must enter a value for the first step. This value essentially sets the geometric size of the simplex and affects the behavior of the algorithm. A good rule of thumb for choosing a value for Delta is $20 \%$ of the size of the entire design space. The minimum and maximum values for each design variable are specified. This will bound the optimizer, preventing it from choosing designs that lie outside this range. Constraints are useful for preventing creation of unrealistic geometry or application of unrealistic boundary or volume conditions. The maximum and minimum values were set as $\pm 10 \%$ for 


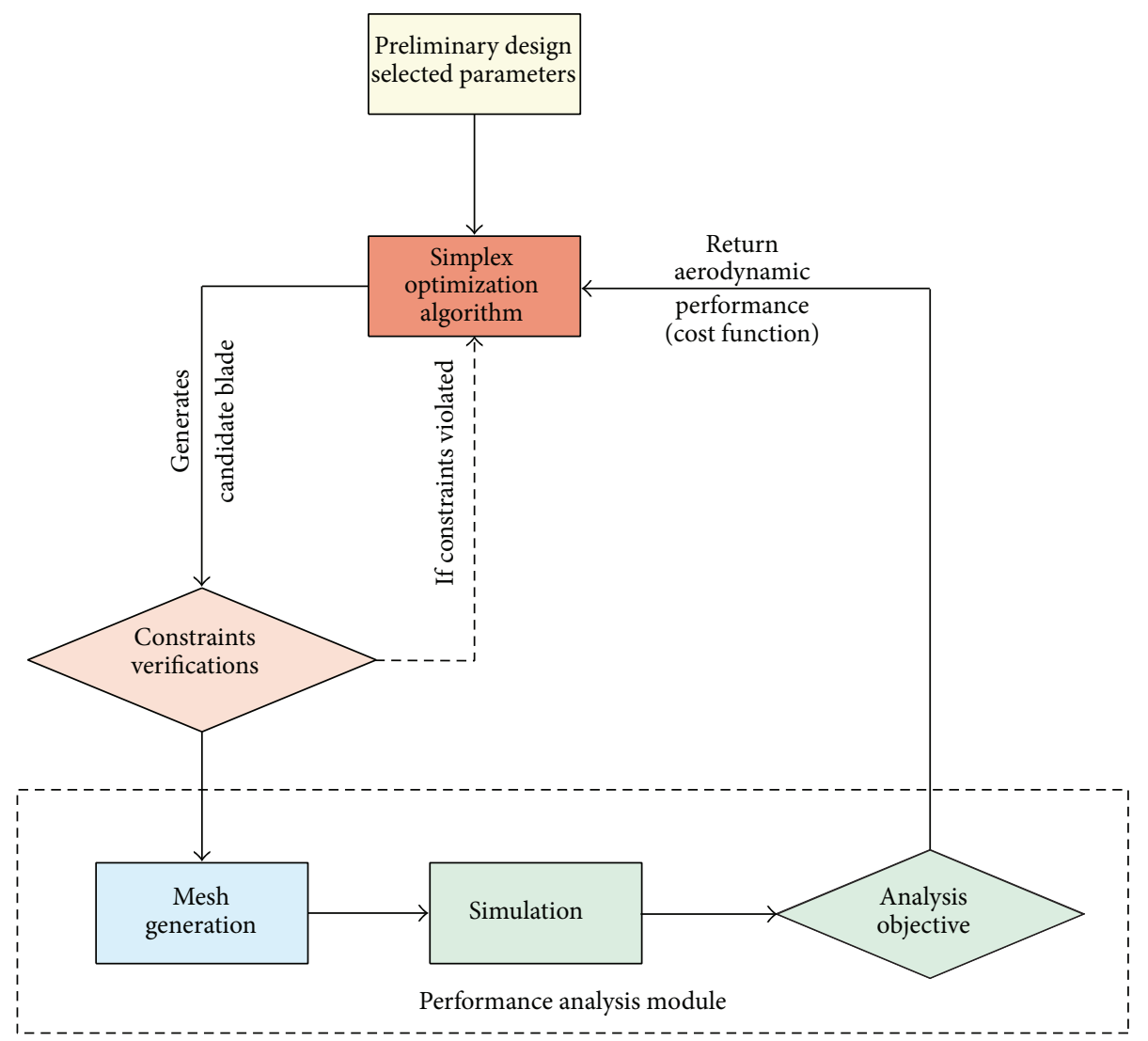

FIGURE 15: A flowchart for the design optimization process.
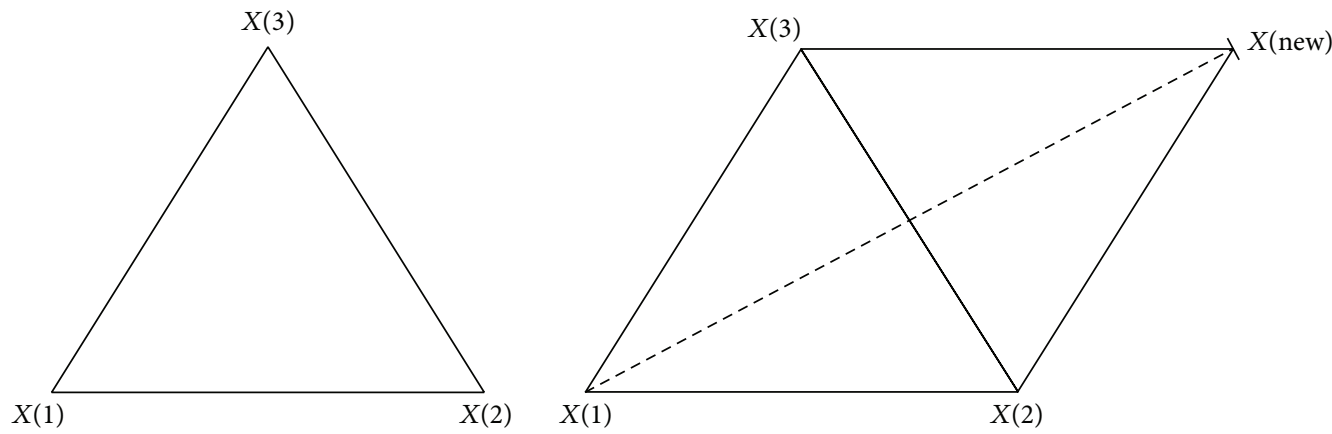

FIGURE 16: New design point in simplex optimization algorithm.

most of the variables such Bezier points coordinates. This cycle is segmented into main steps that were previously developed and programmed. They are as follows.

(i) The low fidelity (preliminary design) is started and the geometry of the new design specified.

(ii) The simplex optimization algorithm starts with the low fidelity optimal as a baseline of optimization.

(iii) The geometry construction variables are imported in CFD-GEOM and geometry is constructed. The constructed geometry is passed through the constraint verifications stage. In this stage the geometry is checked to make sure that it satisfies the constraints. Then, the edge grid is generated and all steps are being carried out by executing the developed grid generation module.

(iv) The boundary condition, initial condition, and solver controls are applied in the simulation module by executing the solver setting module.

(v) Then, the analysis objective module executes. Output of this module is a data file containing values, which is the average value of the cost function and the geometric parameters. 
TABLE 1: Rotor pressure ratio for different grid sizes.

\begin{tabular}{|c|c|c|c|c|c|}
\hline Number of cells & $2 E 5$ & $5 E 5$ & $8 E 5$ & $9 E 5$ & $10 E 5$ \\
\hline Normalized 1st grid spacing & $3.23 E-3$ & $2.0 E-3$ & $1.4 E-3$ & $1.2 E-3$ & $1.1 E-3$ \\
\hline (stage total pressure ratio) & 1.426 & 1.4317 & 1.4327 & 1.433 & 1.4334 \\
\hline
\end{tabular}

(vi) The simplex optimizer continues to run on the other geometry, and the path of the optimization is stored in a data file to monitor the history of results during the optimization run.

All the above steps are arranged and programmed using the PYTHON language and conducted in the simulation manager module, which is one of the modules in the CFDRC package.

\section{Results}

5.1. Low Fidelity Design Results. The current transonic rotor under consideration is a first-stage rotor of a three stage fan recently designed [7]. The baseline data of the fan preliminary design is presented in Table 2 . The results of the preliminary design using low fidelitiy modules are presented in Table 3. The initial estimation of the number of stages indicates that 3 stages are required to obtain an overall pressure ratio of 2.6. A parametric study is performed to investigate the effect of different design parameters on the fan performance and to choose the design parameters such as the rotational speed, blade geometry and the stagger angle of the rotor and stator. The fan performance is computed in terms of the surge margin, fan efficiency and pressure ratio at the design and off-design conditions as shown in Figure 17. The selections that are based on minimum number of stages with maximum isentropic efficiency allow producing the required fan pressure ratio. The three-stage fan is the result of compromise between the isentropic efficiency and tip speed constraint. The fan stages have pressure ratios of $1.55,1.36$, and 1.25 for the 1st, 2nd, and 3rd stages, respectively [7]. Then, the optimization process using the CFD is conducted for the first-stage rotor only in order to reduce the optimization parameters.

5.2. High Fidelity Design Results. The history of the optimization process for the high fidelity design is shown in Figure 18. CFD simulations conducted with and without optimization are presented in Table 4. The difference in pressure ratio and efficiency for the low fidelity rotor in Table 3 and CFD simulation in Table 4 is due to the inaccuracy of the low level models considered in the preliminary design phase. The comparison presented in Table 4 shows an increase in the total pressure ratio by $13.8 \%$. The isentropic efficiency increases as well. The number of blades computed for the optimal design is less than the original low fidelity design by 3 blades.

The high fidelity design is found to lean toward the direction of rotation. The rotor blade is swept forward from the hub to mean portion of the blade and have a backward swept for the rest of the blade as presented in Figure 19.

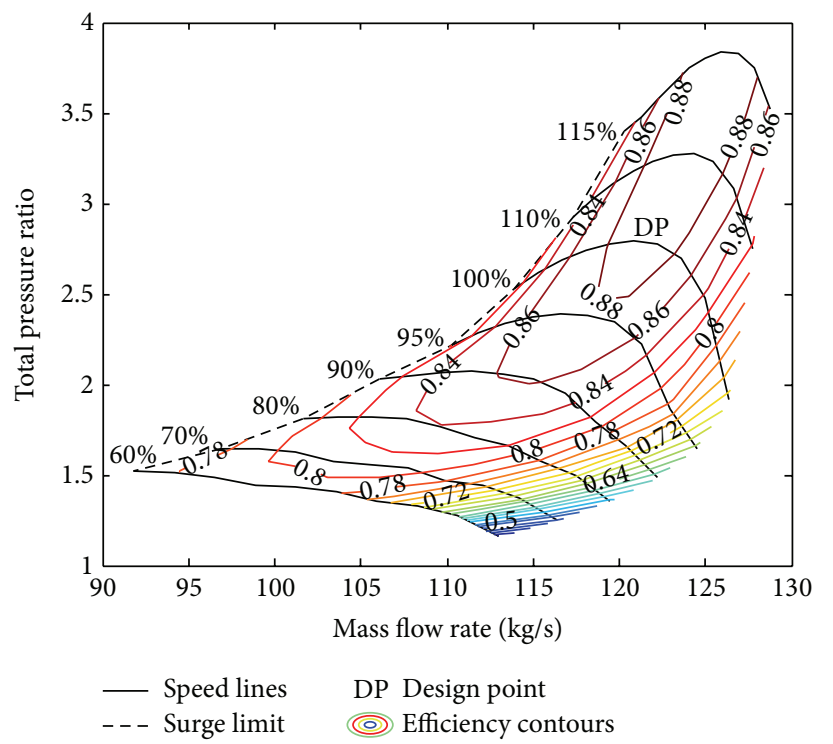

FIGURE 17: Low fidelity fan performance map.

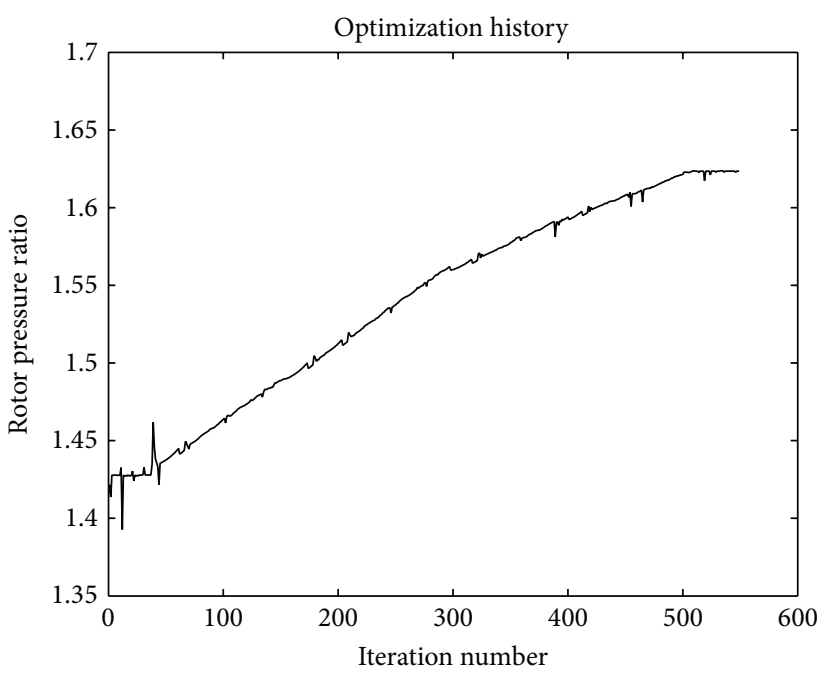

FIGURE 18: Variation of the rotor pressure ratio during the optimization process.

Previous study of [9] concludes that more leaned rotor blade increases the rotor isentropic efficiency and the operating range. The forward swept rotor is found to have higher peak efficiency and a substantially larger stall margin than the baseline of nonsweep rotor.

It is clear from Figure 20 that the blade chord length tends to increases at the hub section. In addition, the stagger angle slightly increases. At the mean section, the chord increases, while the stagger angle remains almost constant. The tip 
TABLE 2: Baseline data of the selected case.

\begin{tabular}{|c|c|c|c|c|c|}
\hline \multicolumn{2}{|c|}{ Requirements } & \multicolumn{2}{|c|}{ Inlet conditions } & \multicolumn{2}{|c|}{ Selected parameters } \\
\hline Mass flow rate & $120 \mathrm{~kg} / \mathrm{sec}$ & Total inlet temperature & $300 \mathrm{~K}$ & $N$ (r.p.m) & $<10500$ \\
\hline \multirow[t]{3}{*}{ Fan pressure ratio } & 2.6 & Total inlet pressure & $101.325 \mathrm{kPa}$ & Hub-to-tip ratio & $0.2-0.7$ \\
\hline & & & & Diffusion factor & $<0.55$ \\
\hline & & & & Inlet axial Mach number & 0.7 \\
\hline
\end{tabular}

TABLE 3: Low fidelity design parameters.

\begin{tabular}{|c|c|c|c|c|c|c|}
\hline \multirow{2}{*}{ Parameter } & \multicolumn{2}{|c|}{ First stage } & \multicolumn{2}{|c|}{ Second stage } & \multicolumn{2}{|c|}{ Third stage } \\
\hline & Rotor & Stator & Rotor & Stator & Rotor & Stator \\
\hline Blades number & 25 & 27 & 34 & 35 & 34 & 35 \\
\hline Mean radius (m) & 0.32 & 0.32 & 0.32 & 0.32 & 0.32 & 0.32 \\
\hline Aspect ratio & 3.45 & 3.15 & 4 & 3.8 & 3.5 & 3.55 \\
\hline Blade height & 0.28 & 0.21 & 0.2 & 0.19 & 0.17 & 0.16 \\
\hline $\mathrm{Hub} /$ tip ratio & 0.39 & 0.49 & 0.52 & 0.53 & 0.57 & 0.6 \\
\hline (r.p.m) & 9,800 & - & 9,800 & - & 9,800 & - \\
\hline Tip speed (m/s) & 450 & - & 411.3 & - & 398 & - \\
\hline$M_{\text {rel }}$ at tip & 1.63 & - & 1.15 & - & 1.08 & - \\
\hline Pressure ratio & \multicolumn{2}{|c|}{1.55} & \multicolumn{2}{|c|}{1.36} & \multicolumn{2}{|c|}{1.25} \\
\hline Isentropic efficiency & \multicolumn{2}{|c|}{0.944} & \multicolumn{2}{|c|}{0.9337} & \multicolumn{2}{|c|}{0.9052} \\
\hline
\end{tabular}

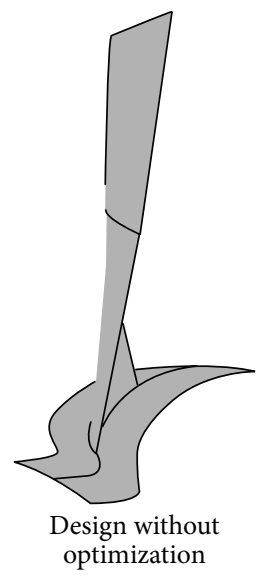

(a)

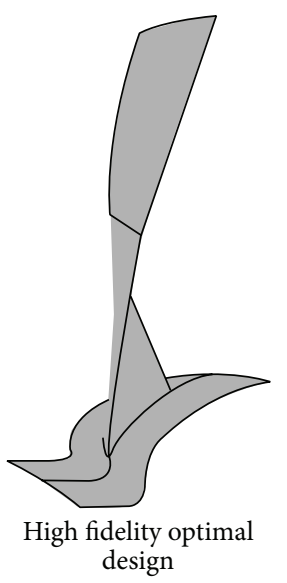

(b)

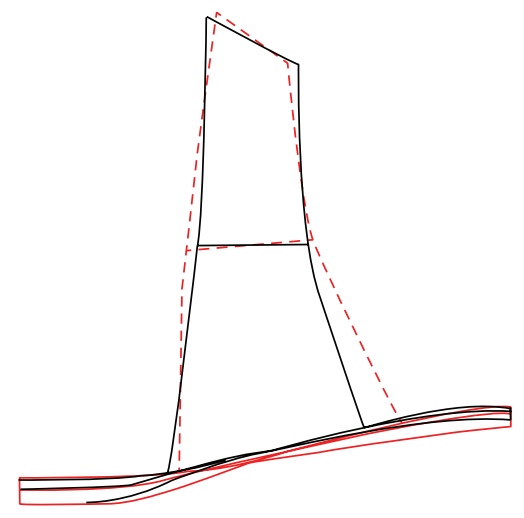

— Low fidelity design - - - High fidelity design

(c)

FIGURE 19: Comparison between the blade shape of the high fidelity optimal design and the design without optimization.

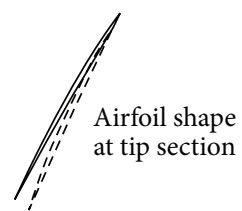

- Low fidelity design
-- - High fidelity design

(a)

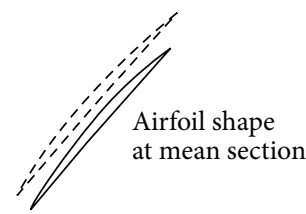

- Low fidelity design
- - High fidelity design

(b)

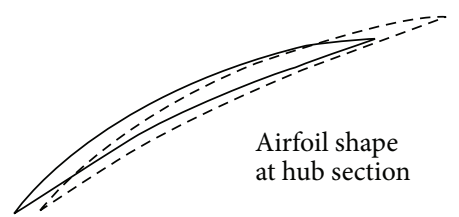

- Low fidelity design
- - High fidelity design

(c)

FIgURE 20: Comparison between airfoil shapes with and without optimization at $0 \%, 50 \%$, and $100 \%$ span from the hub. 


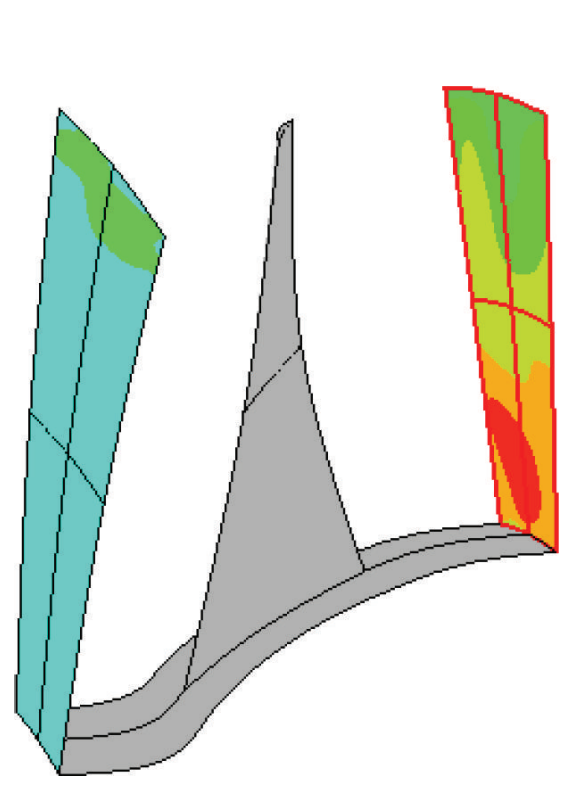

(a) Design without optimization

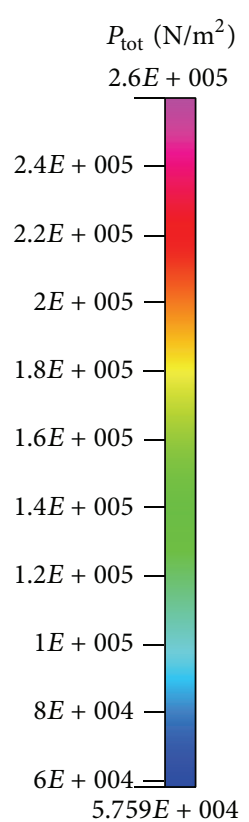

$5.759 E+004$

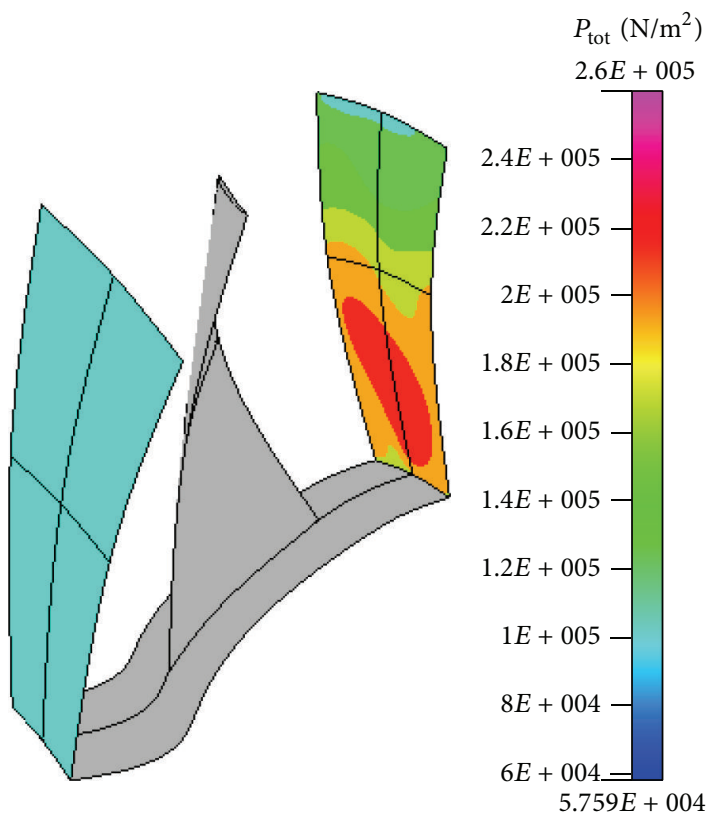

(b) High fidelity optimal design

FIGURE 21: Comparison between total pressure contours for high fidelity and low fidelity designs.

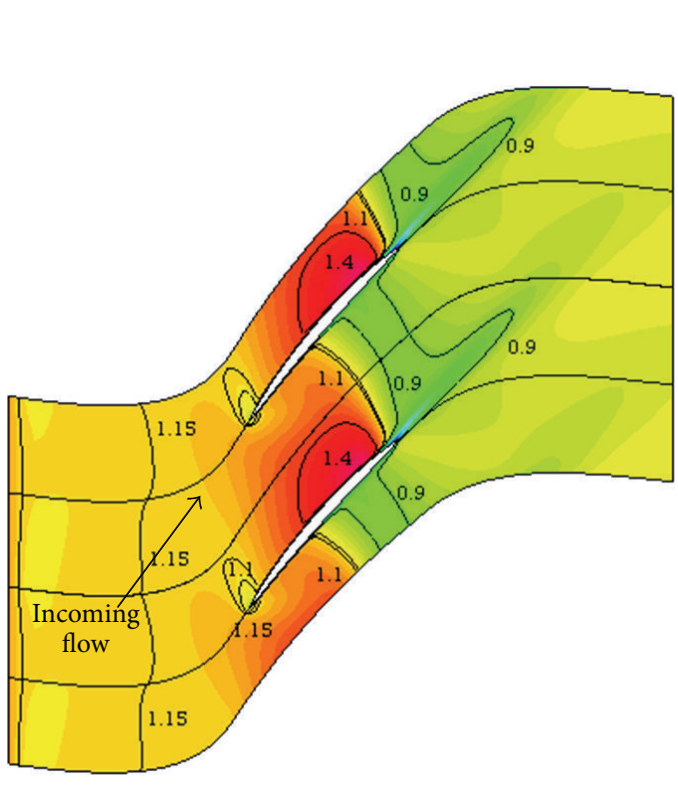

(a) Without optimization

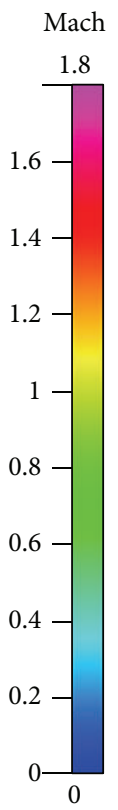

FIGURE 22: Comparison between high fidelity design and low fidelity design Mach contour at mean section. section has a greater stagger angle with a shorter chord length than the low fidelity design.

Similar transonic stages with inlet Mach number of 0.7 to 1.1 limited by a pressure ratio from 1.15 to 1.6 and an isentropic efficiency from $80 \%$ to $85 \%$ are obtained as indicated by Boyce [26]. The isentropic efficiencies decrease with the increase of the inlet relative Mach number. The current transonic rotor produces a pressure ratio of 1.62 .
The total pressure contours at the inlet and exit planes of the rotors are presented in Figure 21. The high fidelity optimal design has a high pressure distribution near the hub region than the low fidelity one.

The Mach number contours of the high fidelity optimal design at the mean section are compared to those of the low fidelity and the results are presented in Figure 22. The high fidelity design has a lower Mach number in front of the 


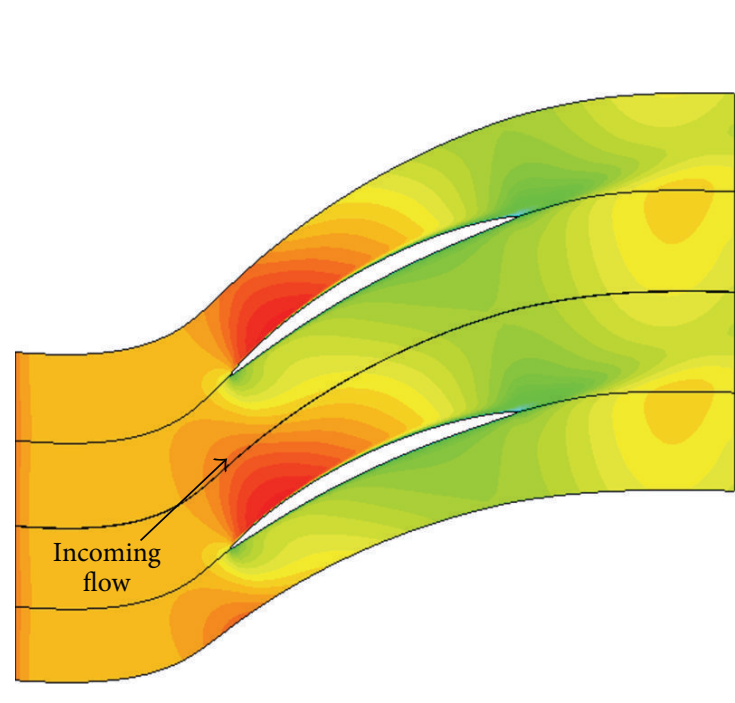

(a) Near hub section

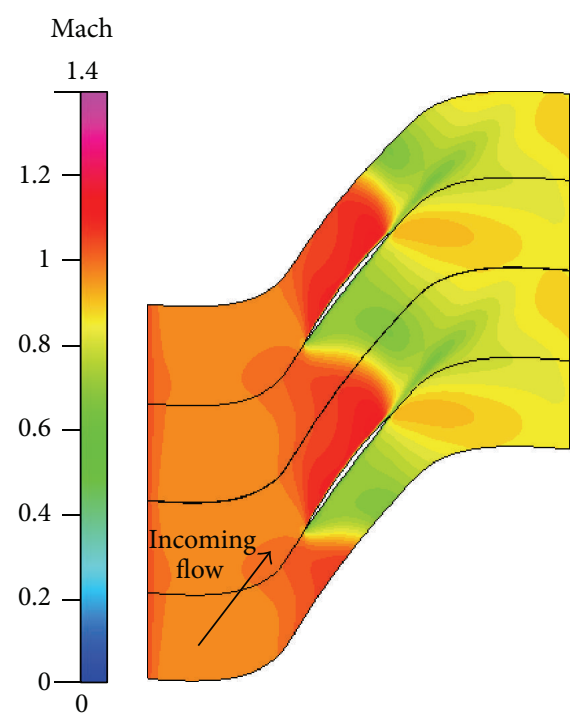

(b) Near tip section

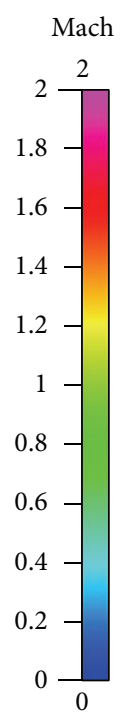

FIGURE 23: High fidelity design Mach contour near the hub (a) and tip (b) sections.
TABLE 4: CFD simulations with and without optimization.

\begin{tabular}{lcc}
\hline & $\begin{array}{c}\text { Without } \\
\text { optimization }\end{array}$ & High fidelity optimum design \\
\hline $\begin{array}{l}\text { Pressure ratio } \\
\begin{array}{l}\text { Isentropic } \\
\text { efficiency }\end{array}\end{array}$ & 1.43 & 1.627 \\
$\begin{array}{l}\text { Leaned } \\
\begin{array}{l}\text { Swept } \\
\text { Numbers of } \\
\text { blades }\end{array}\end{array}$ & Non & $\begin{array}{c}\text { In direction of rotation } \\
\text { Forward swept (hub to mean) } \\
\text { Backward swept (mean to tip) }\end{array}$ \\
\hline
\end{tabular}

passage shock. Thus, the losses across the shock are reduced and the passage shock is moved toward the blade leading edge. The shock system inside the passage is reduced to one strong shock. Researchers explain the shape of the shock at the peak efficiency operation as an oblique shock followed by normal shock $[27,28]$. The location of the normal shock is controlled by the back pressure applied to the rotor.

The same observations are shown in Figure 23(a) near the hub section. Near the tip section of Figure 23(b), the flow enters the passage with relative Mach number of about 1.4. The Mach number in front of the shock reaches 1.55 which reduces to 0.95 after the shock.

Close to the tip section, the shock structure is affected by the tip clearance flow. Figure 24 shows the relative Mach number contours at the tip clearance and how the shock structure at this zone is affected by the tip flow. Figure 25 shows the total pressure contours for four meridional planes at $5 \%, 50 \%, 75 \%$, and $100 \%$ of the tip chord from leading edge, where the tip clearance effect appears strongly at the midchord. The flow path over the blade tip leading edge at $90 \%, 95 \%$, and $100 \%$ span from hub is presented in Figure 26.
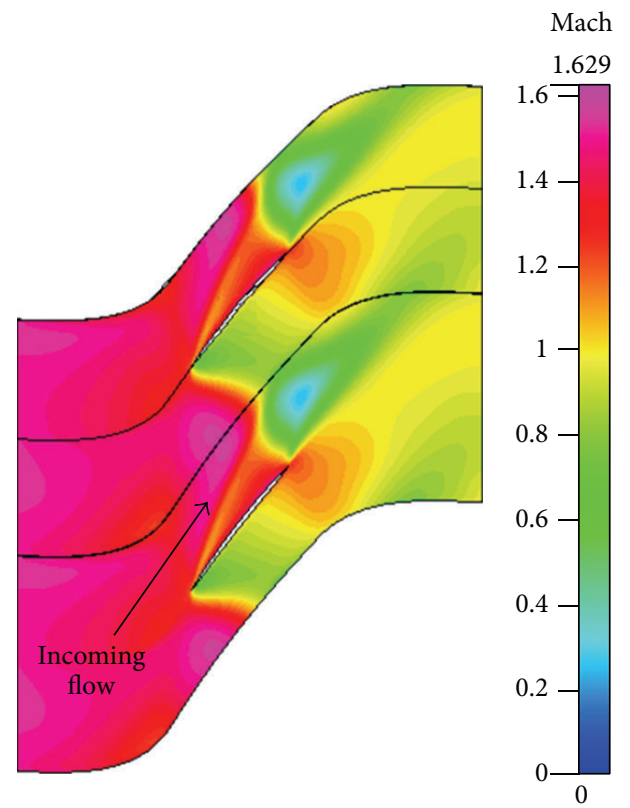

FIGURE 24: High fidelity design Mach contour at tip section.

Because of the very high inflow angle of attack, the main flow cannot follow the direction given by the blade geometry as clear from Figure 26(b). This makes the flow slightly deflect from the suction side. Flow through the tip clearance shown in Figure 26(c) interacts with the deflected flow and decreases significantly the main flow velocity at the tip region.

Figure 27 shows the total pressure contour and velocity vector at the tip clearance region where the effect of the flow through the clearance on the main flow is noticeable.

Performance of the high fidelity optimum design during the off-design operation is presented in Figures 28 and 29. 

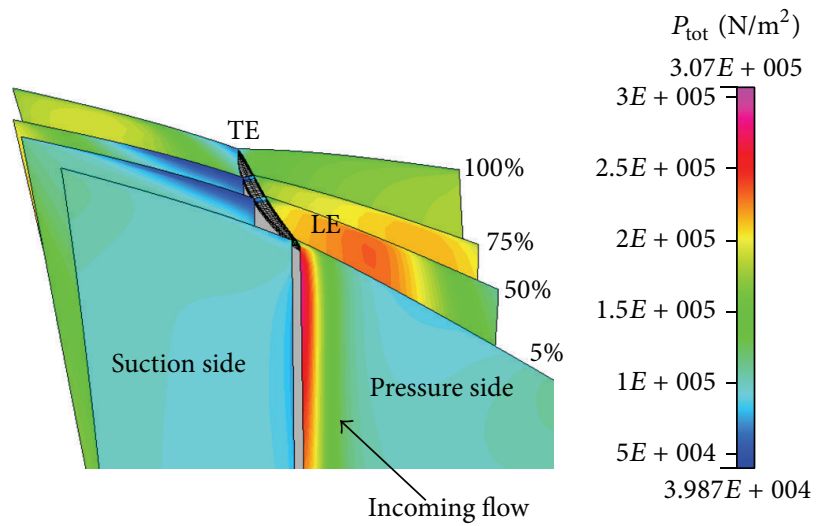

Figure 25: High fidelity design total pressure contours at four meridional planes.

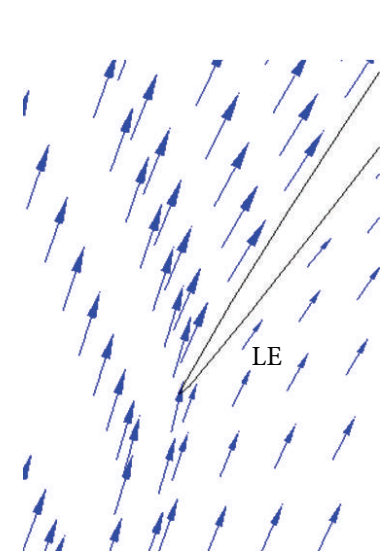

(a) $90 \% \mathrm{Span}$

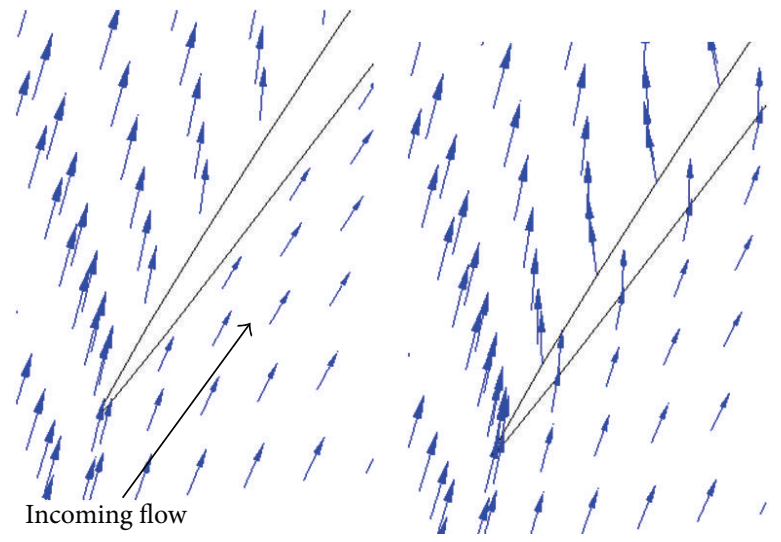

(b) $95 \%$

(c) $100 \%$

FIGURE 26: Flow path at different sections near the blade tip leading edge.

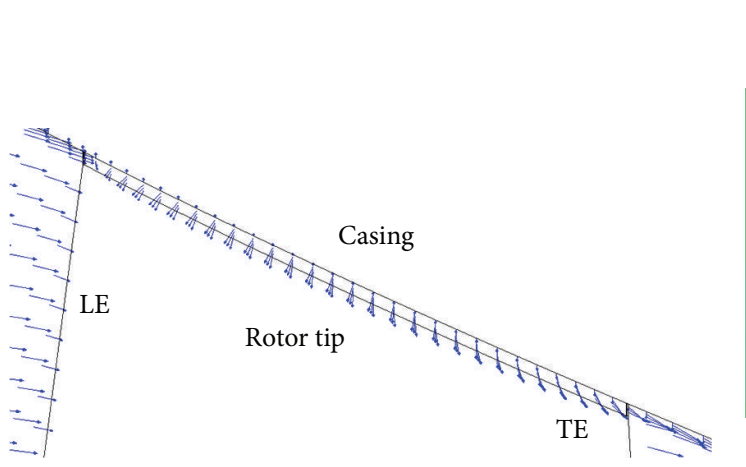

(a)

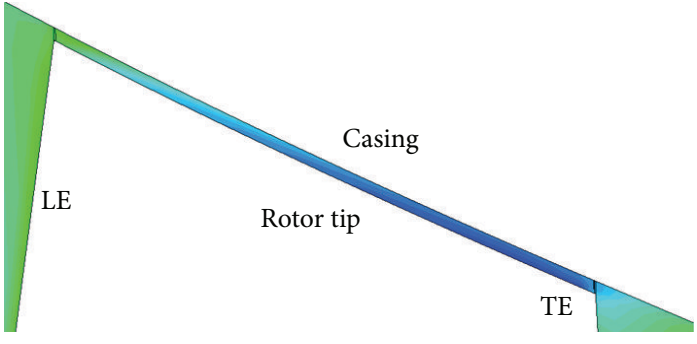

(b)

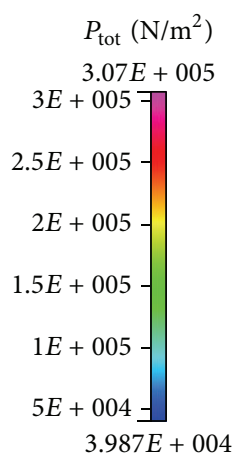

FIGURE 27: Total pressure contour and flow path at the blade tip clearance.
The results show that the total pressure ratio tends to increase with the back pressure to a certain value. As the back pressure is increased, the rotor starts to stall. Decreasing the back pressure increases the isentropic efficiency to certain beak point, then decreases rapidly near the choke point as shown in Figure 29.
The same trend is observed for the different operating speeds but the operation range decreases with the increase in rotor speed. This result sets a limit on the range of the operating speed. The operation range measures the stability of the rotor performance. One of the definitions for the surge margin is that defined by Gostelow et al. [29]. Surge 


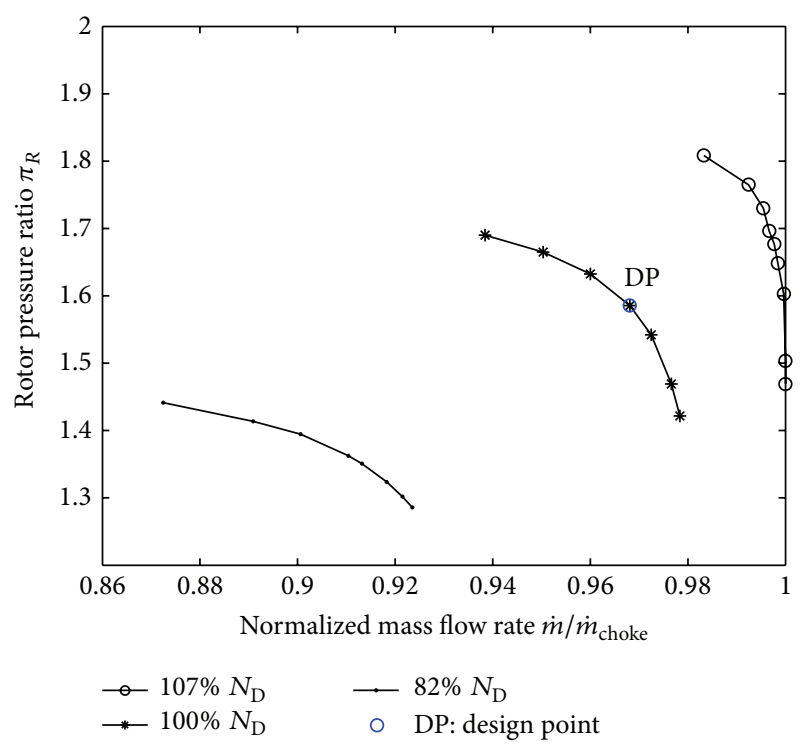

FIGURE 28: Variation of the total pressure ratio with the mass flow rate at different rotational speeds for high fidelity design.

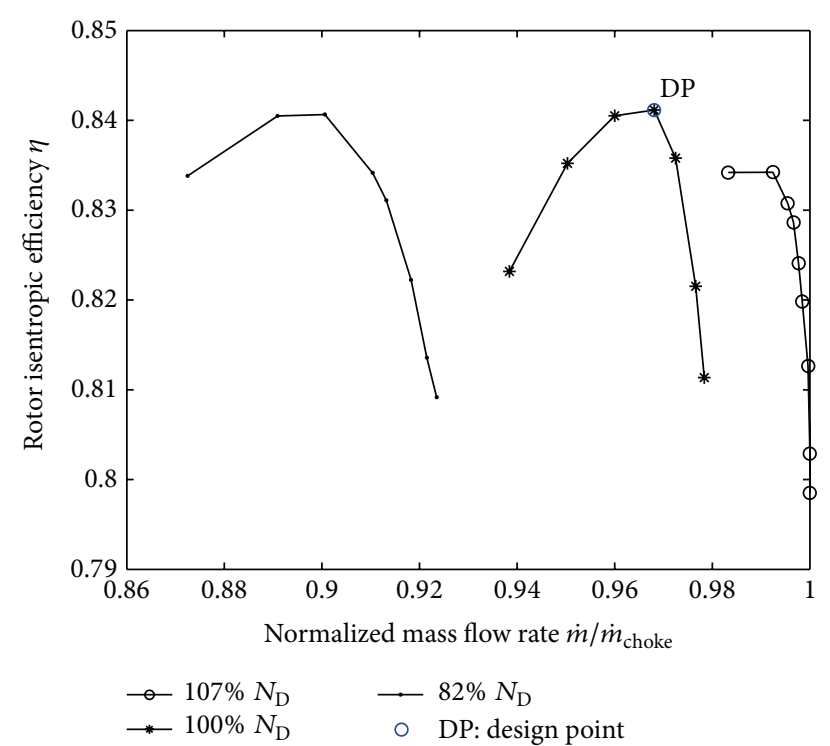

FIgURE 29: Variation of the isentropic efficiency with the mass flow rate at different rotational speeds.

margin depends on the mass flow and the pressure ratio at the operating point. This margin is used to measure the rotor stability. The current design has a $12 \%$ surge margin which is a reasonable value compared to high loaded fans. For high loaded rotors, the surge margin varies from $10 \%$ to $20 \%$ [28].

\section{Conclusion}

In the current study, the design of a transonic fan is optimized using numerical simulation of the compressibleviscous flow equations and simplex optimization algorithm. The results obtained using the CFDRC code are verified with the experimental data of Rotor 67. A grid sensitivity analysis is performed for the numerical simulations. The cost function of the optimization process is the rotor total pressure ratio. The blade geometry is defined in terms of set of optimization groups describing the section chord, stagger angle, staking position, the section thickness, and camber distributions. The original total number of variables for the three sections is 84 . The optimum design is found to be leaned in the direction of rotation and has a forward sweep from the hub-to-mean section and backward sweep to the tip. The pressure ratio increased by $14 \%$ at the design speed and mass flow rate. The peak efficiency increments were numerically observed using a blade prevalently curved towards the direction of rotation and slightly backward inclined near the tip. A fewer number of blades is achieved to reduce the rotor weight. The performance of the new design shows a stable operation during a wide range in the off design.

\section{Conflict of Interests}

The authors declare that there is no conflict of interests regarding the publication of this paper.

\section{References}

[1] A. Oyama, M.-S. Liou, and S. Obayashi, "Transonic axialflow blade optimization: evolutionary algorithms/three-dimensional Navier-Stokes solver," Journal of Propulsion and Power, vol. 20, no. 4, pp. 612-619, 2004.

[2] Y. Lian and M.-S. Liou, "Multi-objective optimization of transonic compressor blade using evolutionary algorithm," Journal of Propulsion and Power, vol. 21, no. 6, pp. 979-987, 2005.

[3] Y. Lian and N.-H. Kim, "Reliability-based design optimization of a transonic compressor," AIAA Journal, vol. 44, no. 2, pp. 368$375,2006$.

[4] A. Oyama, L. M. Liou, and S. Obayashi, "High fidelity swept and leaned rotor blade design optimization using evolutionary algorithm," in Proceedings of the 16th AIAA Computational Fluid Dynamics Conference, Orlando, Fla, USA, 2003.

[5] C. Hah and L. Reid, "A viscous flow study of shock-boundary layer interaction, radial transport, and wake development in a transonic compressor," Journal of Turbomachinery, vol. 114, no. 3, pp. 538-547, 1992.

[6] F. Ning and L. Xu, "Numerical investigation of transonic compressor rotor flow using an implicit 3D flow solver with oneequation Spalart-Allmaras turbulence model," in Proceedings of the ASME Turbo Expo: Power for Land, Sea, and Air, New Orleans, La, USA, 2001.

[7] M. A. Aziz, F. M. Owis, and M. M. Abdelrahman, "Preliminary design of a transonic fan for low by-pass turbofan engine," International Review of Aerospace Engineering, vol. 6, no. 2, pp. 114-127, 2013.

[8] A. R. Wadia and W. W. Copenhaver, "An investigation of the effect of cascade area ratios on transonic compressor performance," Journal of Turbomachinery, vol. 118, no. 4, pp. 760-770, 1996.

[9] R. Biollo and E. Benini, "Recent advances in transonic axial compressor aerodynamics," Progress in Aerospace Sciences, vol. 56, pp. 1-18, 2013. 
[10] C. Hah, D. C. Rabe, and A. R. Wadia, "Role of tip-leakage vortices and passage shock in stall inception in a swept transonic compressor rotor," in Proceedings of the ASME Turbo Expo: Power for Land, Sea, and Air, pp. 545-555, Vienna, Austria, June 2004.

[11] S. L. Puterbaugh, W. W. Copenhaver, C. Hah, and A. J. Wennerstrom, "A three-dimensional shock loss model applied to an aftswept, transonic compressor rotor," Journal of Turbomachinery, vol. 119, no. 3, pp. 452-459, 1997.

[12] A. J. Strazisar, J. R. Wood, M. D. Hathaway, and K. L. Suder, "Laser anemometer measurements in a transonic axial-flow fan rotor," NASA Technical Paper 2879, NASA, 1989.

[13] C.-M. Jang, P. Li, and K.-Y. Kim, "Optimization of blade sweep in a transonic axial compressor rotor," Journal of Thermal Science and Technology International B, vol. 48, no. 4, pp. 793801, 2006.

[14] C. Hah, S. L. Puterbaugh, and A. R. Wadia, "Control of shock structure and secondary flow field inside transonic compressor rotors through aerodynamic sweep," in Proceedings of the International Gas Turbine \& Aeroengine Congress \& Exhibition, pp. 1-15, Stockholm, Sweden, June 1998.

[15] A. R. Wadia, P. N. Szucs, and D. W. Crall, "Inner workings of aerodynamic sweep," Journal of Turbomachinery, vol. 120, no. 4, pp. 671-682, 1998.

[16] J. Bergner, S. Kablitz, D. K. Hennecke, H. Passrucker, and E. Steinhardt, "Influence of sweep on the 3D shock structure in an axial transonic compressor," in Proceedings of the ASME Turbo Expo: Power for Land, Sea, and Air, pp. 343-352, Reno, Nev, USA, June 2005.

[17] S. Kablitz, H. Passrucker, D. K. Hennecke, and M. Engber, "Experimental analysis of the influence of sweep on tip leakage vortex structure of an axial transonic compressor stage," in Proceedings of 16th International Symposium on Air-Breathing Engines (ISABE '03), Cleveland, Ohio, USA, 2003.

[18] E. Benini and R. Biollo, "Aerodynamics of swept and leaned transonic compressor-rotors," Applied Energy, vol. 84, no. 10, pp. 1012-1027, 2007.

[19] R. Biollo and E. Benini, "Impact of sweep and lean on the aerodynamic behavior of transonic compressorrotors," in Proceedings of the 4th International Conference on Future of Gas Turbine Technology, Brussels, Belgium, 2008.

[20] E. Benini and R. Biollo, "Effect of forward and aft lean on the performance of a transonic compressor rotor," International Journal of Turbo and Jet Engines, vol. 25, no. 1, pp. 13-26, 2008.

[21] C.-S. Ahn and K.-Y. Kim, "Aerodynamic design optimization of an axial flow compressor rotor," in Proceedings of the ASME Turbo Expo: Power for Land, Sea, and Air, pp. 813-819, Amsterdam, The Netherlands, June 2002.

[22] Q. Bai, "Analysis of particle swarm optimization algorithm," Computer and Information Science, vol. 3, no. 1, pp. 180-184, 2010.

[23] B. E. Launder and D. B. Splading, Lectures in Mathematical Models of Turbulence, Academic Press, London, UK, 1972.

[24] J. Dunham, "CFD validation for propulsion system components," AGARD Advisory Report 355, 1998.

[25] P. J. Roache, "Perspective: a method for uniform reporting of grid refinement studies," Journal of Fluids Engineering, vol. 116, no. 3, pp. 405-413, 1994.

[26] M. P. Boyce, Gas Turbine Engineering Handbook, ButterworthHienemann, 2nd edition, 2003.
[27] K. M. Boyer, An improved streamline curvature approach for offdesign analysis of transonic compression systems [Ph.D. thesis], Virginia Polytechnic Institute and State University, Blacksburg, Va, USA, 2001.

[28] G. S. Bloch, Flow losses in supersonic compressor cascades [Ph.D. thesis], Virginia Polytechnic Institute and State University, Blacksburg, Va, USA, 1996.

[29] J. P. Gostelow, K. W. krabacber, and L. H. Smith Jr., Performance Comparisons of High Mach Number Compressor Rotor Blading, National Aerodynamics and Space Administration, Washington, DC, USA, 1968. 

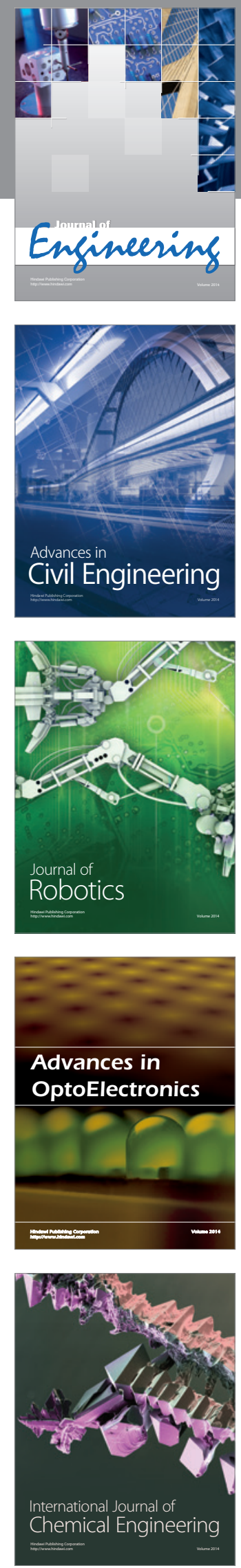

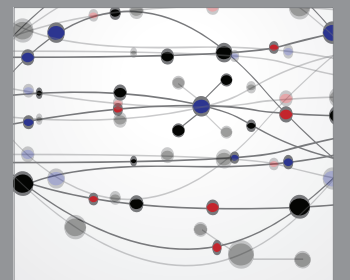

The Scientific World Journal
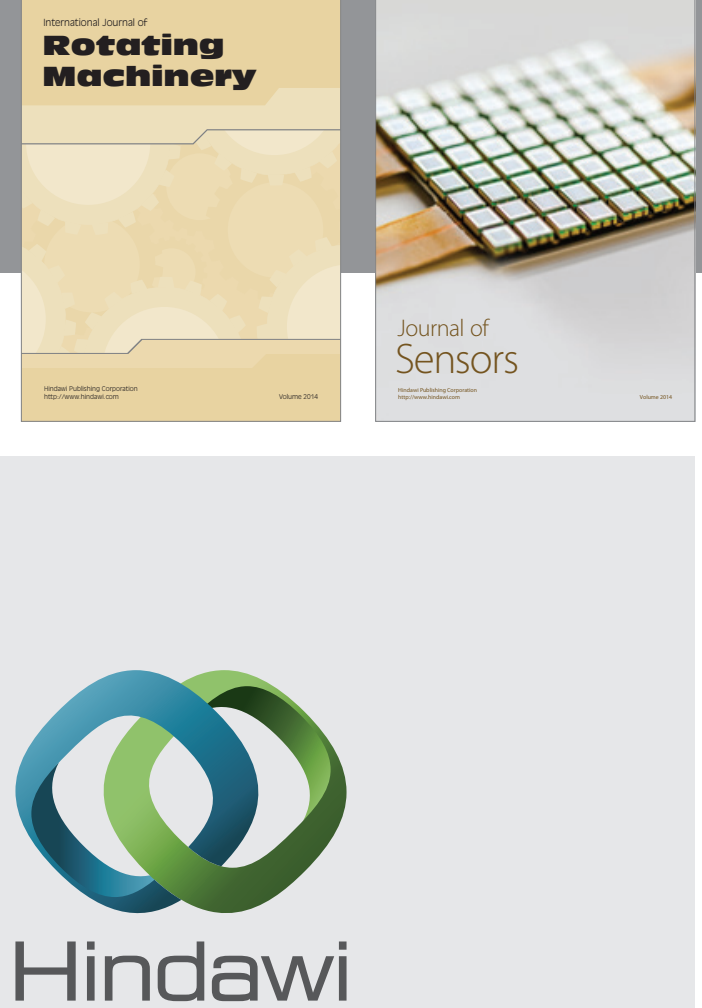

Submit your manuscripts at http://www.hindawi.com
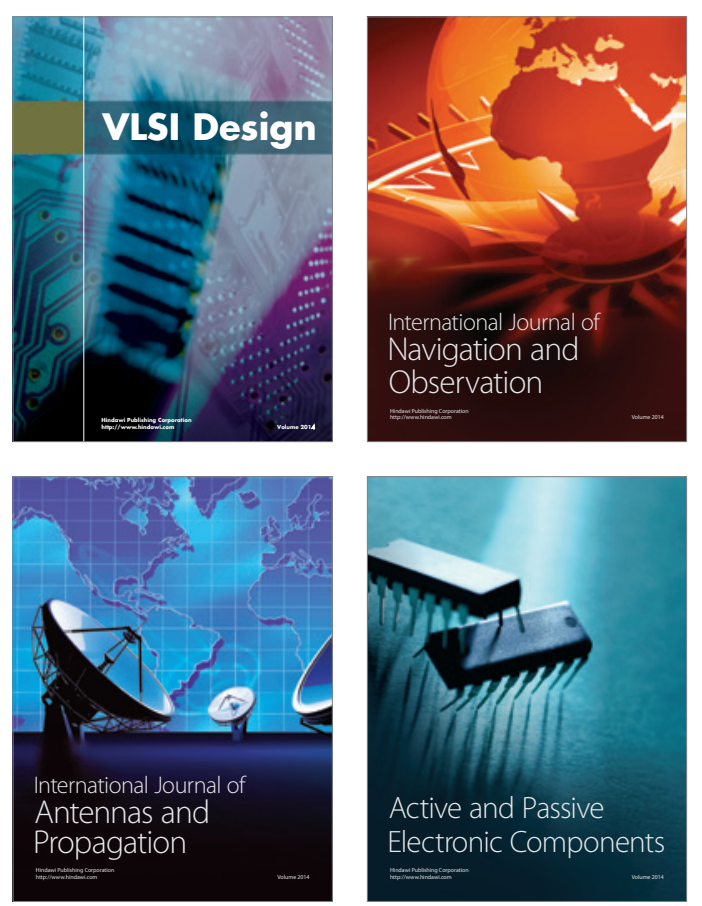
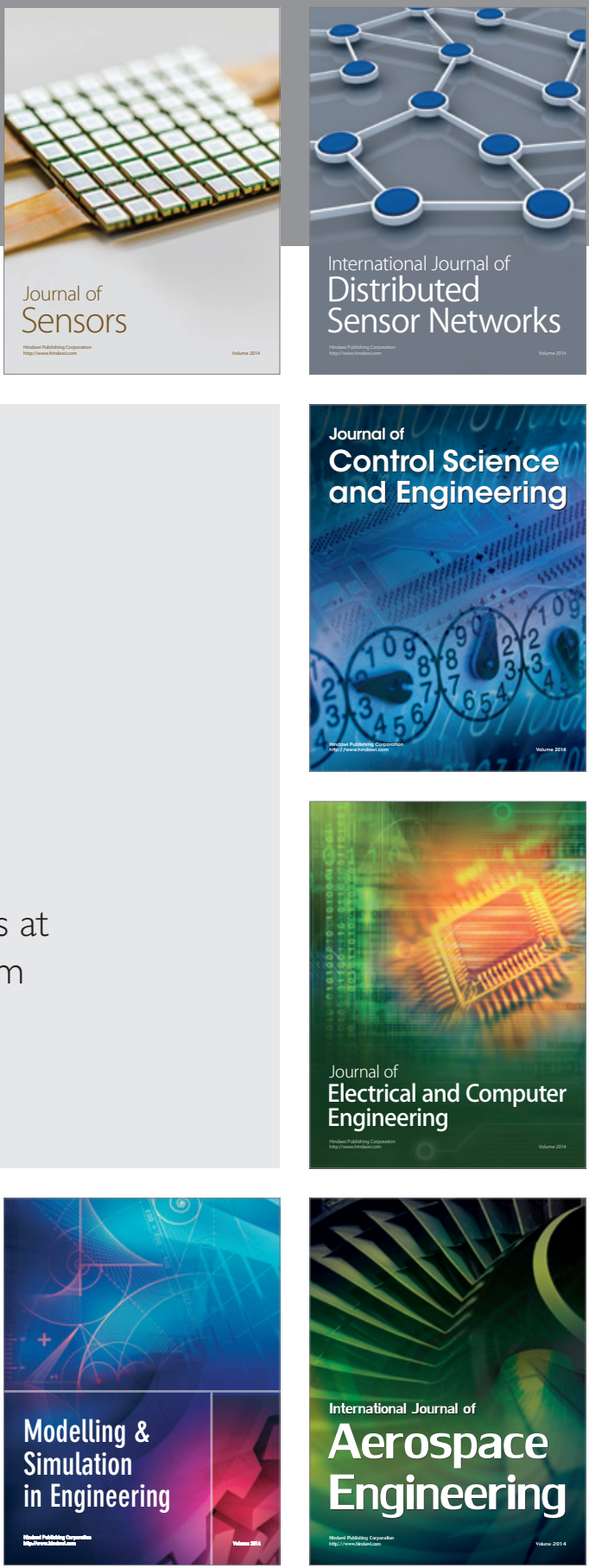

Journal of

Control Science

and Engineering
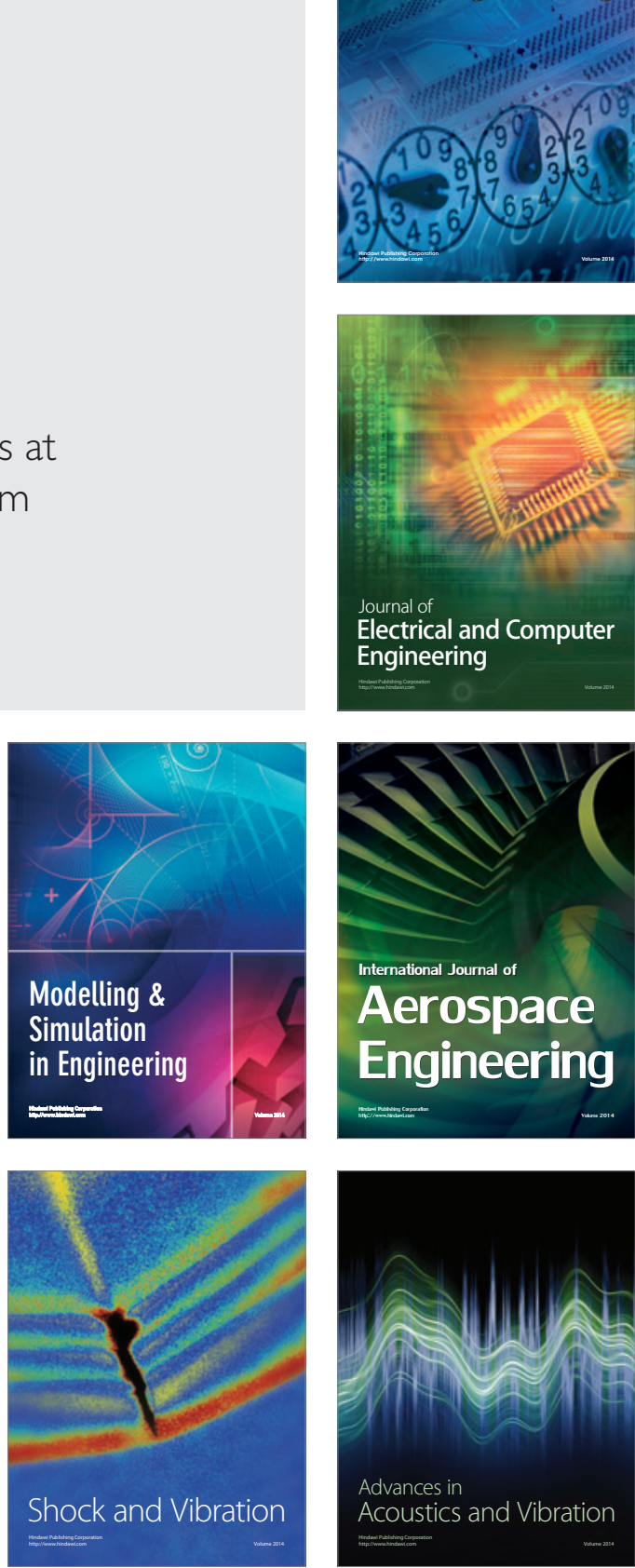